\title{
An Experimental Game of Loss Sharing
}

\author{
Wulf Gaertner ${ }^{\mathrm{a}, \mathrm{b}}$, Lars Schwettmann ${ }^{\mathrm{c}, \mathrm{d}}$, Yongsheng $\mathrm{Xu}{ }^{\mathrm{e}}$
}

${ }^{a}$ Corresponding author: University of Osnabrück, Department of Economics, Rolandstraße 8, D-49069 Osnabrück, Germany. E-mail: Wulf.Gaertner@uni-osnabrueck.de. Telephone: +49(0)345 969-2641.

${ }^{b}$ CPNSS, London School of Economics, London WC2A 2AE, UK

${ }^{c}$ Institute for Health Economics and Health Care Management, Helmholtz Zentrum München GmbH, Postfach 1129, D-85758 Neuherberg, Germany.

${ }^{d}$ Martin Luther University Halle-Wittenberg, Department of Economics, Universitätsring 3, D-06108 Halle (Saale), Germany

${ }^{e}$ Georgia State University, Andrew Young School of Policy Studies, Department of Economics, P.O. Box 3992, Atlanta, GA 30302-3992, U.S.A.

\begin{abstract}
We conduct a lab-experimental study of bargaining over the distribution of monetary losses. Groups of four differently endowed participants must agree, as a group, on the contribution each participant will make to cover a financial loss imposed on the group. The study sheds light on burden sharing and what loss allocation rules groups adopt. Furthermore, we characterize a new theoretical model which contains the proportional rule and equality of losses as special cases but collides with the constrained equal awards rule. The combination of our model and the constrained equal awards rule can explain the majority of proposals made in our experiment.
\end{abstract}

Keywords: loss sharing; axiomatic characterization of allocation rules; experimental bargaining

JEL classification: C91, D31, D63, D71

Acknowledgements: We are extremely grateful to our colleagues Jaume Marhuenda Beltran, Dorothea Kübler, Ashley Piggins, Antonio Romero Medina, and Georg Weizsäcker for giving us the possibility to run our experiments at the labs of their departments. For very helpful discussions and suggestions, we also wish to thank Marlies Ahlert, Tim Goldmann, Achim Hendriks, Peter König, Felix Meickmann, Taïeb Mellouli, Hendrik Nieß, Vjollca Sadiraj, Katharina Friederike Sträter and Christoph Wunder. Lars Schwettmann is grateful to the Department of Economics at the Martin Luther University for generous financial support. 


\section{Introduction}

The typical scenario of a bargaining problem is a situation where agents who possess an initial endowment - their status quo - come together in order to jointly bring about an outcome which is supposed to be superior to their individual initial position and which each of them would not have been able to achieve just by his or her own productive effort alone. More technically, a bargaining situation is characterized by a (compact and convex) set of production possibilities, often described in terms of potentially feasible utility allocations, a status quo position before collaboration and at least one point of joint production which is strictly better for each agent than their own initial situation. John Nash (1950), Ehud Kalai and Meir Smorodinsky (1975), Alvin Roth (1979), Michael Maschler and Menahem Perles (1981), and several others have offered seminal solution concepts in this field.

This cooperative environment has been worth exploring because of its relevance in many reallife situations where people have conflicting interests but nevertheless are interested in mutually beneficial interaction. This, however, is not the scenario we wish to focus on in this paper. We consider cases where several agents who possess some initial endowment face a situation where they are asked, perhaps forced, to give something away so that they will no longer be able to keep their status quo allocation. Such cases have only rarely been considered in economics. Closest to what we have in mind, though still substantially different, are cases of bankruptcy and bequest situations. In the former, various agents have claims of differing size against a bank or firm and the liquidation value that remains is not sufficient to satisfy all entitlements. In the latter, a father, let's say, made promises to his children but after his death, the heirs find out that the estate he left behind is not large enough to honor all promises.

There are a few theoretical concepts which prescribe how the deficit or loss should be shared. Most prominent is the proportional solution, but also the egalitarian rule, the constrained equal awards solution, the constrained equal losses rule and the "contested garment" principle received considerable attention (for a characterization of these rules see, among others, Robert Aumann and M. Maschler (1985), Carmen Herrero and Antonio Villar (2001), and William Thomson $(2003,2013))$. In addition, there are a few questionnaire results as well as findings from experimental games for such situations. Across all empirical investigations, the proportional division of an overall loss turned out to be what most agents were willing to agree to but in cases where the discrepancy in the claims vector became larger, there was a tendency towards equality in final outcomes (Simon Gächter and Arno Riedl (2006), Kristof Bosmans and Erik Schokkaert (2009), Herrero, Juan Moreno-Ternero, and Giovanni Ponti (2010)).

We should mention that apart from the three publications just mentioned, there exists a relatively small literature in which the distribution of losses has been experimentally investigated as well, but these situations were staged almost always within two-person relationships so that they differ significantly from our own scenario. Most prominent among these are investigations set-up as an ultimatum game (Nancy Buchan et al. (2005), Xiaolin Zhou and Yan Wu (2011), Roger Berger et al. (2012)). Bernhard Borges and Jack Knetsch (1997) report the results of two experiments in which participants acted as arbitrators in a series of disputes over gains and losses between two parties. Eric van Dijk et al. (1999) present questionnaire results about the distribution of net profits and net losses among business partners on a flea market. 
Our own experimental set-up is closely related to a study that two of the present authors did on burden sharing in countries that suffered from a severe financial crisis that gained momentum after the collapse of Lehman Brothers in 2008 (Gaertner and Schwettmann, 2016). All these countries, in particular Cyprus, Greece, Ireland, Portugal and Spain introduced programs that became known as a policy of austerity where the population had to face all kinds of cuts in old-age retirement benefits, pensions, health coverage, and extra-payments which had been granted to them over many years. The experimental game of losses that we present in this paper by no means claims to be able to cover and depict such an overall economic situation in detail, but it is our hope that our simple set-up can, at least to some extent, mirror some of the features with which the general public was faced in those countries. We believe that the issue of loss division or burden sharing is of a much more general nature. It may become a real challenge for those who will be concerned. Without being more specific, we just mention the large number of refugees from Africa, Asia and the Near East who are heading for Europe in order to evade severe droughts or military conflicts or just hope for a more prosperous future. Another issue that will definitely concern future generations is the question where to deposit the nuclear waste coming from nuclear power plants either active or about to be dismantled shortly.

Section 2 introduces a new theoretical model and its axiomatic characterization. We will show that this model together with the rule of "constrained equal awards" helps to distinguish solutions that we gained from our experimental results. Section 3 provides a description of our simple game of losses and introduces the methods used to analyze the data. Section 4 contains the results. Descriptive statistics of group outcomes will be presented first. Then, we will focus on individual proposals, classify them with regard to the different models, and relate the proposals to the position of the proposer in the group and the demographic data that we were able to obtain. The paper ends with a few concluding remarks. The game protocol and the detailed results that we gathered at different universities are relegated to an appendix.

\section{Theory}

Are there models that could describe and possibly predict the bargaining behavior of agents involved in a situation where losses have to be shared? As already mentioned in the introduction, the proportional solution, the constrained equal awards rule, and the constrained equal losses rule appear to be candidates to describe and analyze the agents' behavior in such circumstances. In the following, we put forward a new model which contains the proportional rule as a special case but clearly collides with the constrained equal awards rule. Given our experimental set-up which we will describe after this section, it also contains the constrained equal losses rule as a special case.

\subsection{Basic setup}

A society consists of $n \geq 2$ individuals. $N=\{1, \cdots, n\}$ denotes the individuals in the society. Each individual $i \in N$ is endowed with a certain amount of resources, money in this case, 
$\omega_{i} \geq 0$. The society incurs a loss $L$ with $0<L \leq \sum_{i \in N} \omega_{i} .\left(L,\left(\omega_{1}, \cdots, \omega_{n}\right)\right)$ is called a problem. Throughout this section, $L$ is given and fixed. Since $L$ is given, we shall write a generic problem as $\left(\omega_{1}, \cdots, \omega_{n}\right)$.

Let $\Xi$ denote the following set of problems:

$$
\left\{\left(\omega_{1}, \cdots, \omega_{n}\right):\left(0<L \leq \sum_{i \in N} \omega_{i}\right),\left(\omega_{i} \geq 0 \forall i \in N\right)\right\} .
$$

For any problem $\xi=\left(\omega_{1}, \cdots, \omega_{n}\right) \in \Xi$, let

$$
\mu(\xi)=\frac{\omega_{1}+\cdots+\omega_{n}}{n}
$$

denote the mean of $\omega_{1}, \cdots, \omega_{n}$. For any $\bar{\mu}>0$, let $\Xi(\bar{\mu})$ denote the set

$$
\left\{\xi=\left(\omega_{1}, \cdots, \omega_{n}\right) \in \Xi: \mu(\xi)=\bar{\mu}\right\} .
$$

A sharing rule, $f: \Xi \rightarrow \mathbf{R}^{n}$, is such that, for each $\xi=\left(\omega_{1}, \cdots, \omega_{n}\right) \in \Xi,\left[f_{i}(\xi) \in \mathbf{R}\right.$ for all $i \in$ $N]$ and $\left[\sum_{i \in N} f_{i}(\xi) \geq L\right]$.

A sharing rule $f$ is the $\left(\frac{L}{n}, \mu\right)$-referenced rule if, for each $\bar{\mu}>0$, there exists $\alpha$ such that

$$
\forall \xi=\left(\omega_{1}, \cdots, \omega_{n}\right) \in \Xi(\bar{\mu}), \quad \forall i \in N: f_{i}(\xi)=\frac{L}{n}+\alpha\left(\omega_{i}-\mu(\xi)\right) .
$$

Therefore, the $\left(\frac{L}{n}, \mu\right)$-referenced rule uses the average "burden" to everyone, $\frac{L}{n}$, as the reference and then adds to this reference level a proportion of the gap between an individual's endowment and the mean of individuals' endowments to compute individual $i$ 's share.

Remark 1. It may be noted that if $\alpha=0$ or if there is equality in initial endowments, the $\left(\frac{L}{n}\right.$, $\mu)$-referenced rule becomes the equal-division rule.

Remark 2. It may be noted that $\alpha$ depends on the mean of endowments. In particular, when $\alpha=\frac{L}{n \mu}$, then $f_{i}(\xi)=\alpha \omega_{i}$ for all $i \in N$, and, as a consequence, the $\left(\frac{L}{n}, \mu\right)$-referenced rule becomes the proportional rule.

\subsection{Axioms}

Symmetry: For all $\xi=\left(\omega_{1}, \cdots, \omega_{n}\right) \in \Xi$, if $\omega_{1}=\cdots=\omega_{n}$, then $f_{1}(\xi)=\cdots=f_{n}(\xi)$.

Independence of Rank-and-Mean-Preserving Changes: For all $\xi=\left(\omega_{1}, \cdots, \omega_{n}\right)$ and $\xi^{\prime}=$ $\left(\omega_{1}^{\prime}, \cdots, \omega_{n}^{\prime}\right) \in \Xi$ with [for all $i, j \in N, \omega_{i} \leq \omega_{j} \Rightarrow \omega_{i}^{\prime} \leq \omega_{j}^{\prime}$, if $\mu(\xi)=\mu\left(\xi^{\prime}\right)$, then, for any $i \in N,\left[\omega_{i}=\omega_{i}^{\prime} \Rightarrow f_{i}(\xi)=f_{i}\left(\xi^{\prime}\right)\right]$.

Efficiency: For all $\xi=\left(\omega_{1}, \cdots, \omega_{n}\right) \in \Xi, \sum_{i \in N} f_{i}(\xi)=L$. 
Monotonicity in Contributions: For all $\varepsilon \in \mathbf{R}$, there exists a continuous function $g: \mathbf{R} \rightarrow \mathbf{R}$ such that, for all $i \in N$, all $\xi=\left(\omega_{1}, \cdots, \omega_{n}\right)$ and $\xi^{\prime}=\left(\omega_{1}^{\prime}, \cdots, \omega_{n}^{\prime}\right) \in \Xi$, if $\mu(\xi)=\mu\left(\xi^{\prime}\right)$ and $\omega_{i}^{\prime}=\omega_{i}+\varepsilon$, then $f_{i}\left(\xi^{\prime}\right)=f_{i}(\xi)+g(\varepsilon)$.

Symmetry says that if everyone has the same endowments, then they should share the loss equally.

Independence of Rank-and-Mean-Preserving Changes requires that, for two sets of endowments with the same mean and the same rank order of the individuals in terms of their endowments, if an individual has the same amount of endowments in the two situations, then this individual's share of the loss should be the same.

Efficiency merely requires that the total contributions by all the players must be the loss that is to be shared.

Monotonicity in Contributions requires that the incremental change of an individual's contribution to the share of the loss depends on the net change of his endowments if, after the possible change of individuals' endowments, the mean remains unchanged.

\subsection{Theoretical result}

Theorem 2.1 A sharing rule $f$ on $\Xi$ satisfies Symmetry, Independence of Rank-and-MeanPreserving Changes, Efficiency and Monotonicity in Contributions if and only if it is the $\left(\frac{L}{n}, \mu\right)$-referenced rule.

Proof. It can be checked that the $\left(\frac{L}{n}, \mu\right)$-referenced rule satisfies Symmetry, Independence of Rank-and-Mean-Preserving Changes, Efficiency and Monotonicity in Contributions. In what follows, we shall show that, if a sharing rule $f$ on $\Xi$ satisfies Symmetry, Independence of Rank-and-Mean-Preserving Changes, Efficiency and Monotonicity in Contributions, then it is the $\left(\frac{L}{n}, \mu\right)$-referenced rule.

Let $f$ on $\Xi$ satisfy Symmetry, Independence of Rank-and-Mean-Preserving Changes, Efficiency and Monotonicity in Contributions. We show that $f$ is the $\left(\frac{L}{n}, \mu\right)$-referenced rule.

Let $\xi=\left(\omega_{1}, \cdots, \omega_{n}\right) \in \Xi$ and consider $\xi^{\mu}=\left(\omega_{1}^{\mu}, \cdots, \omega_{n}^{\mu}\right) \in \Xi$ such that $\left[\omega_{i}^{\mu}=\mu(\xi)\right.$ for all $i \in N]$. By Symmetry and Efficiency,

$$
f_{i}\left(\xi^{\mu}\right)=\frac{L}{n} \text { for all } i \in N .
$$

Consider $\max \left\{\omega_{1}, \cdots, \omega_{n}\right\}$ and $\min \left\{\omega_{1}, \cdots, \omega_{n}\right\}$. If $\max \left\{\omega_{1}, \cdots, \omega_{n}\right\}=\min \left\{\omega_{1}, \cdots, \omega_{n}\right\}$, then $\omega_{i}=\mu(\xi)$ for all $i \in \mathrm{N}$. It then follows immediately that, in this case, for all $\mathrm{i} \in \mathrm{N}$

$$
f_{i}(\xi)=\frac{L}{n}+\alpha\left(\omega_{i}-\mu(\xi)\right) \text { for any } \alpha .
$$


Suppose now that $\max \left\{\omega_{1}, \cdots, \omega_{n}\right\}>\min \left\{\omega_{1}, \cdots, \omega_{n}\right\}$. Without loss of generality, let $\omega_{n}=$ $\max \left\{\omega_{1}, \cdots, \omega_{n}\right\}$ and $\omega_{1}=\min \left\{\omega_{1}, \cdots, \omega_{n}\right\}$. Let $\varepsilon=\min \left\{\omega_{n}-\mu(\xi), \mu(\xi)-\omega_{1}\right\}$. Note that $\varepsilon>0$.

Consider the case in which $\varepsilon=\omega_{n}-\mu(\xi)$ first. Take any $\varepsilon_{1}, \varepsilon_{2} \in[0, \varepsilon]$ such that $\varepsilon_{1}+\varepsilon_{2}=\varepsilon$ and three problems $\xi^{1}=\left(\omega_{1}^{1}, \cdots, \omega_{n}^{1}\right), \xi^{2}=\left(\omega_{1}^{2}, \cdots, \omega_{n}^{2}\right), \xi^{3}=\left(\omega_{1}^{3}, \cdots, \omega_{n}^{3}\right) \in \Xi$ such that

$$
\begin{array}{cccc}
\omega_{1}^{1}=\mu(\xi)-\varepsilon_{1}, & \omega_{n}^{1}=\mu(\xi)+\varepsilon_{1}, & \omega_{j}^{1}=\mu(\xi) & \forall j \in N \backslash\{1, n\} \\
\omega_{1}^{2}=\mu(\xi)-\varepsilon_{2}, & \omega_{n}^{2}=\mu(\xi)+\varepsilon_{2}, & \omega_{j}^{2}=\mu(\xi) \quad \forall j \in N \backslash\{1, n\} \\
\omega_{1}^{3}=\mu(\xi)-\varepsilon, & \omega_{n}^{3}=\mu(\xi)+\varepsilon, & \omega_{j}^{3}=\mu(\xi) \quad \forall j \in N \backslash\{1, n\} .
\end{array}
$$

By Monotonicity in Contributions, there exists a continuous function $g: \mathbf{R} \rightarrow \mathbf{R}$ such that

$$
f_{n}\left(\xi^{1}\right)=f_{n}\left(\xi^{\mu}\right)+g\left(\varepsilon_{1}\right), \quad f_{n}\left(\xi^{2}\right)=f_{n}\left(\xi^{\mu}\right)+g\left(\varepsilon_{2}\right)
$$

and

$$
f_{n}\left(\xi^{3}\right)=f_{n}\left(\xi^{\mu}\right)+g\left(\varepsilon_{1}+\varepsilon_{2}\right), \quad f_{n}\left(\xi^{3}\right)=f_{n}\left(\xi^{1}\right)+g\left(\varepsilon_{2}\right) .
$$

From equation (2), we have

$$
f_{n}\left(\xi^{\mu}\right)+g\left(\varepsilon_{1}+\varepsilon_{2}\right)=f_{n}\left(\xi^{1}\right)+g\left(\varepsilon_{2}\right) .
$$

Noting equation (1), we then obtain

$$
g\left(\varepsilon_{1}+\varepsilon_{2}\right)=g\left(\varepsilon_{1}\right)+g\left(\varepsilon_{2}\right)
$$

This is the Cauchy equation. Its unique solution is given by (see Aczél (1966)):

$$
\text { for all } \mathrm{t} \geqslant 0, g(t)=\alpha t \text { for some constant } \alpha \text {. }
$$

Therefore,

$$
f_{n}\left(\xi^{3}\right)=f_{n}\left(\xi^{\mu}\right)+\alpha\left(\omega_{n}-\mu(\xi)\right)=\frac{L}{n}+\alpha\left(\omega_{n}-\mu(\xi)\right) .
$$

By Independence of Rank-and-Mean-Preserving Changes and noting that $\omega_{n}^{3}=\mu(\xi)+\varepsilon=$ $\omega_{n}$ in this case, we have

$$
f_{n}(\xi)=f_{n}\left(\xi^{3}\right)=\frac{L}{n}+\alpha\left(\omega_{n}-\mu(\xi)\right)
$$

By Independence of Rank-and-Mean-Preserving Changes and noting that $\mu(\xi)=\mu\left(\xi^{3}\right)$ and $\omega_{i}^{3}=\mu(\xi)$ for all $i \in N \backslash\{1, n\}$, we also have

$$
\forall i \in N \backslash\{1, n\}: f_{i}\left(\xi^{\mu}\right)=f_{i}\left(\xi^{3}\right)=\mathrm{L} / \mathrm{n}
$$

Applying the above arguments to $f_{1}$ and noting that, for the case analyzed here, $\varepsilon=\omega_{n}-$ $\mu(\xi)=\min \left\{\omega_{n}-\mu(\xi), \mu(\xi)-\omega_{1}\right\}$, we can obtain

$$
f_{1}\left(\xi^{3}\right)=f_{1}\left(\xi^{\mu}\right)-\alpha\left(\omega_{n}-\mu(\xi)\right) .
$$


Now, consider $\max \left\{\omega_{1}, \cdots, \omega_{n-1}\right\}$. Without loss of generality, let $\omega_{n-1}=\max \left\{\omega_{1}, \cdots, \omega_{n-1}\right\}$. By repeating the procedures for $f_{1}$ and $f_{n}$ above, we can show that

$$
f_{1}(\xi)=L / n+\alpha\left(\omega_{1}-\mu(\xi)\right), \text { if } \min \left\{\omega_{n-1}-\mu(\xi), \mu(\xi)-\omega_{1}^{3}\right\}=\mu(\xi)-\omega_{1}^{3}
$$

or

$$
f_{n-1}(\xi)=L / n+\alpha\left(\omega_{n-1}-\mu(\xi)\right) \text {, if } \min \left\{\omega_{n-1}-\mu(\xi), \mu(\xi)-\omega_{1}^{3}\right\}=\omega_{n-1}-\mu(\xi) .
$$

And by repeating the above, we can obtain

$$
\text { for all } i \in N: f_{i}(\xi)=\frac{L}{n}+\alpha\left(\omega_{i}-\mu(\xi)\right)
$$

The case in which $\varepsilon=\mu(\xi)-\omega_{1}$ can be dealt with analogously to the above argument, and we can obtain equation (5) as well. This completes the proof.

In the section that follows, our experimental game is presented where $n$ is set equal to four. In the base game, there is equality in initial endowments. In the analysis, we shall, however, focus on a situation of unequal endowments.

\section{Methods}

\subsection{A game of losses and the experimental setup}

The detailed protocol of our game on loss sharing and the complete instructions given to the participants can be found in Appendix A1. In each experimental session, participants are assigned to a group of four individuals. Starting from an initial distribution of endowments in terms of real money (Euros), a loss has to be shared. The initial endowment in the base game is 10 Euros for each player. The group is then asked to give back a total of 10 Euros to the experimenter. In our variant of this game with unequal endowments on which this paper focuses in particular, a total amount of 50 Euros is distributed randomly to the four participants in each group where the assignment vector is $(5,10,15,20)$. Again, the players are informed that a total amount of 10 Euros has to be handed back to the experimenter.

One randomly chosen member within each group will have to make a first proposal of how to distribute the loss of 10 Euros among the members of this group. Proposals that lead to individual losses higher than a person's initial endowment are not accepted. After this first proposal, the other members of the group are asked to either accept or reject the proposal. These players have one minute to make a decision. Should they remain "silent", this will be taken as acceptance of the proposal. If the proposal is accepted by all members of the group, the experiment is over for these four players.

Should there be no agreement after the first round, i.e. at least one of the three other group members objects, a second person in this group, again determined by chance but, of course, different from the first, will have to make a proposal of how to split up the loss of 10 Euros. As long as no agreement on some proposal is reached among the group members, a new person is randomly chosen to propose a distribution of the loss. 
Whenever at any point in the game, one proposal receives unanimous agreement, the experiment is over and the procedure is as described above. There is a 20-minute time limit for each experiment. If after 20 minutes, no past proposal received unanimous support, the experiment is terminated automatically. In this case, a random mechanism will pick one of the past proposals as the final decision on the share of the loss. Participants are aware of this and any other time limit during the experiment.

Finally, at the end of each game, students were asked to answer a few questions that concerned personal data, namely age, gender, family income in the past, future expected income and own political orientation. The last three answers had to be indicated on scales ranging from 1 (low resp. left) to 7 (high resp. right).

\section{[Table 1 here]}

We ran our experimental game on loss sharing between October 2015 and June 2016 at the Technical University of Berlin, the University of Ireland in Galway, the University of HalleWittenberg, and the University Carlos III in Madrid. Table 1 provides an overview of all sessions. Almost all students who participated in these experiments were enrolled in either economics or business administration and had been invited by our local collaborators. Overall, we had 35 groups of four players each. We ran five experiments at the universities of Berlin and Halle with an equal endowment among all players within a group. In such a situation, it would be strange to expect anything different from an equal share of the loss, but we wanted to confirm that the general setting of the game is coherent and that departures from equal share are mainly triggered by the unequal endowment in our main situation. In fact, after a few rounds all five groups agreed on an equal split of the losses. Therefore, our focus is on the 30 groups that faced the situation of unequal endowment.

In each session, all students entered the room together and were randomly placed at the computers so that they could not identify the other members of their group of four. At the beginning of the experiment, the experimenter read the instructions aloud and students could follow the text on their computer screen. Then they could ask questions. The bargaining process for all groups did not start until all questions had been answered.

The endowments were randomly assigned to the four participants in each group. Due to the structure of our experiment, some groups reached an agreement quite early while other groups used the entire 20 minutes. However, all students in a session had to stay and remain silent until the last group had finished the experiment in order to guarantee anonymity. At the end of the experiment, students had to jointly leave the room. After a couple of minutes, they were invited to successively enter the room again and receive their final net amount in an envelope with their personal code number in order to preserve complete anonymity. The entire experiment usually lasted about 45 minutes plus the payment procedure. The average earning was 12.50 Euros in situations with unequal endowments and 7.50 Euros in the case of equal endowments. 


\subsection{Statistical methods}

How would or could a proposal or a final solution to our experimental game look like? A priori, "everything" can happen as long as the participants are not primed in one way or another, which was not the case in our series of experiments. Nevertheless, we are mainly interested in the support for either of the two models, namely the constrained equal awards rule (CEA) and the behavioral rule described and characterized in section 2 . For the initial endowment vector $(5,10,15,20)$, the CEA rule prescribes a loss vector of $(0,0,2.5,7.5)$. In contrast, our new model prescribes the following loss vectors for four different values of parameter alpha:

$$
\begin{array}{lc}
(2.5,2.5,2.5,2.5) \text { for } \alpha=0, & (1,2,3,4) \text { for } \alpha=1 / 5, \\
(0.625,1.825,3.125,4.375) \text { for } \alpha=1 / 4, & \text { and }(0,12 / 3,31 / 3,5) \text { for } \alpha=1 / 3 .
\end{array}
$$

In our example, $\alpha=0$ leads to equality of losses, whereas $\alpha=1 / 5$ results in proportionality in loss shares. Furthermore, $\alpha=1 / 3$ yields a solution in which the person with the lowest endowment is exempted from carrying any losses. In the case of $\alpha=1 / 4$, the higher endowed persons carry a larger burden compared to proportionality while no group member is completely exempted.

Clearly, one cannot expect players to propose exactly the loss shares yielded by the last two alpha values, but we think that a final solution of, for example, $(0,2,3,5)$ is "close" to the case of $\alpha=1 / 3$ and a solution of $(0.5,2,3,4.5)$ is "close" to the case of $\alpha=1 / 4$. In the same vein, the loss vector $(0,0,3,7)$ is "close" to the CEA solution. As we will report in section 4 , we observe indeed several corresponding solutions.

To make such "closeness" considerations more precise, we take up an idea that was employed in one of Gächter and Riedl's (2006) studies, namely to calculate for any proposal that was made the absolute difference expressed by the Euclidean distance of this answer from CEA on one side and from the four versions our model on the other.

In a first step, we focus on final group outcomes, classify all non-random solutions with respect to their distance to the closest of the rule-based vectors of concern, and comment on specific characteristics of these allocations of losses.

In a second step, rather than focusing on final results we look at all proposals that were made during all rounds. We think that it is worthwhile to study how these intermediate proposals that did not necessarily lead to a final solution on which all members of the group agreed looked like in relation to CEA and our model. We follow again Gächter and Riedl (2006) and rank our rule-based solutions according to their absolute difference towards each proposed vector of allocated losses.

In a third step, we shed light on possible explanations for the implicit choice of a rule. Hence, similar to the second step we consider again which of the rule-based solutions is closest to an allocation of losses proposed and relate this information to socio-demographic characteristics of the corresponding proposer, but also to group-specific attributes including his endowment, the number of previous rounds, and the place of the experiment. First, we use non-parametric tests to compare the distribution of answers on the five rule-based solutions between different groups of respondents. Second, we estimate a multinomial logistic regression model in which 
the five solutions form the categories of the dependent variable while the individual and group-specific characteristics serve as controls. We report marginal effects to give an impression of the strength of the effect observed. In each case, variance inflation factors are calculated to assess the severity of potential multicollinearity. According to David J. Sheskin (2011), a value above 5 would suggest a problem, but in our case the factors are always clearly below this threshold. All analyses have been conducted with the software package STATA ${ }^{\text {TM }}$ (version 14). The programming and conduction of the experiment was done with the web-based "Software Platform for Human Interaction Experiments (SoPHIE ${ }^{\mathrm{TM}}$ )" offered by SoPHIE Labs (www-sophielabs.com).

\section{Experimental results}

To structure the presentation of our results for the case of unequal endowments, we begin by describing the final allocations of all groups with such endowments. Afterwards, we turn to all individual proposals irrespective of acceptance or rejection by the other group members. An overview of all proposals and reactions can be found in Table A2 in the Appendix.

\subsection{Group decisions: Descriptive results}

Table 2 provides an overview of the outcomes of all 30 sessions with unequal endowments. Nine of these groups did not reach an agreement so that the final allocation was decided at random. In column 3 of Table 2, the final loss vector is specified for each group, given that there was unanimous agreement within 20 minutes. Note that for the individual loss, we use $\mathrm{L}_{\mathrm{i}}$ as a short form of what we denoted as $f_{i}(\xi)$ in the theoretical model in Section 2. For example, $L_{5}$ refers to the final loss of the player with the lowest initial endowment. Column 4 reports the number of rounds played in each group. The corresponding values vary remarkably. While in six groups all members accepted the very first proposal, in two other groups it took 16 rounds to reach unanimous agreement.

\section{[Table 2 here]}

Column 5 specifies the proposer of a final solution to which everyone agreed. For example, $\mathrm{P}_{15}$ means that the final proposal was made by the player who had an initial endowment of 15 Euros. The probability of acceptance by all other group members does not depend on the endowment of the proposer. On the one hand, this is certainly due to the fact that there is strict anonymity so that respondents are not aware of any information about the proposer including his or her endowment. On the other hand, it seems that even participants with high endowment are able to identify allocations which are acceptable for individuals with low endowments.

Finally, the last two columns of Table 2 relate the proposals to the different theoretical models. As already explained in subsection 3.2, we calculate the Euclidean distance between the final loss vector for all non-random solutions and the closest vector corresponding to any of the five rule-based solutions whose underlying model is also stated in Table 2. As expected, 
individuals prefer to state allocations by using integer values as is the case for the proportional solution. Hence, it is remarkable that three groups reached agreement on a vector which exactly corresponds to the CEA solution $(0,0,2.5,7.5)$.

If we postulate, admittedly somewhat arbitrarily, that a value between zero and one for the Euclidean distance defines closeness, then out of 21 final (non-random) solutions, we would have six solutions supported by CEA and seven solutions supported by our model. If we allow a higher value to be acceptable, we get more support for either rule and could, similarly to Gächter and Riedl (2006), finally classify each proposal accordingly.

A note of caution is necessary, however. A higher upper value of this distance also indicates a larger distance of the proposal from the corresponding rule-based solution. Just as an example, the loss allocation $(0,0.75,3,6.25)$ is quite far away from what CEA prescribes. The CEA rule and our model represent different views of how losses should be shared. While CEA tends to equalize final outcomes by sparing or exempting those at the lower end, our model requires, at least in the realm of those alpha values that we consider, positive contributions from almost everyone, proportionality in burden sharing being one of the options. Nevertheless, the Euclidean distance simply states that an allocation proposed is closer to one rule-based solution compared to any alternative solution considered. Hence, we will follow this interpretation in the next subsection.

\subsection{Individual proposals: Descriptive results}

Above, we were focusing on final outcomes and saw that in many cases the CEA rule and our model got substantial support. This, however, is not the full picture. If, for the moment, we ignore those cases that led to random solutions, Table 2 has already shown that in many other cases, several rounds were needed until a unanimous decision was reached. Consequently, in a second step we also want to look at proposals that were made during all rounds.

However, let us first consider those allocations of losses which we call "antagonistic". Off and on, a proposal was made that assigned the full burden to one single player, in particular to the person with the highest endowment. Whenever such a proposal was made, either once or several times, either by the same player or by several members of this group, the chances were very high that the final solution after 20 minutes was determined randomly. More precisely, eight out of ten experiments with an antagonistic proposal were finally decided via a random mechanism. One interpretation for this fact is that such proposals tended to elicit "nasty" counter-proposals so that the psychological climate within this group "went down the drain".

Table A2 and Table A3 in the Appendix give more details. A particularly illustrative example for this kind of behavior is group 2 in Berlin. In round 9, player $\mathrm{P}_{20}$ (i.e., the player with an initial endowment of 20 Euros) proposed the loss vector $(5,5,0,0)$. In the next round, $\mathrm{P}_{5}$ proposed $(0,0,0,10)$. Then $\mathrm{P}_{10}$ proposed $(0,1,3,6)$ which was rejected by $\mathrm{P}_{20}$. In the following two rounds, $\mathrm{P}_{15}$ proposed a proportional split $(1,2,3,4)$ which was rejected by all the others. In round 14 , player $\mathrm{P}_{20}$ proposed $(0,10,0,0)$ which got rejected; it would have left $\mathrm{P}_{10}$ with 
nothing. In the following four rounds, either $\mathrm{P}_{10}$ or $\mathrm{P}_{5}$ made proposals which would have placed the bulk of the loss on $\mathrm{P}_{20}$ 's shoulders. This was, of course, rejected by $\mathrm{P}_{20}$ but out of solidarity or not, $\mathrm{P}_{15}$ went along with this decision. In the remaining rounds, $\mathrm{P}_{20}$ again proposed twice to put the burden exclusively on $\mathrm{P}_{10}$. In the following analyses, we exclude all 23 antagonistic proposals. Obviously, underlying motives of such proposers clearly differ from the ones of our model and CEA.

\section{[Table 3 here]}

Next, we rank the rule-based solutions according to their distance to each proposal. Table 3 gives the respective results for the remaining 214 proposals. It turns out that the proposals are best approximated by our model within the interval $1 / 4 \leq \alpha \leq 1 / 3$, which can be seen from the mean values of the Euclidean distance and also from the mean ranks for these alpha-values. In fact, 72 out of 214 proposals are best described by our model with $\alpha=1 / 3$, while the model with $\alpha=1 / 4$ ranks highest or second-highest for 121 proposals. In contrast, the equal losses option with $\alpha=0$ does not perform well.

Results are mixed for CEA. This rule fares well with respect to first rank but it is the worst predictor for proposals in 89 cases. Consequently, the mean rank of CEA is rather weak. Hence, a model that mildly charges participants with low endowment seems to be a good predictor for many proposals, while for some individuals either CEA or proportionality seems to be more attractive.

\subsection{Individual proposals and confounding factors}

In the third step, we come back to the first-ranked theoretical solutions and try to elucidate at least some potential explanations for the allocations proposed during the bargaining procedure and the implicit choice of a particular theoretical model. From the structure and the proceeding of our experiment some potentially relevant factors are rather obvious, including the endowment of a proposer, the number of rounds played before a particular proposal or the site of the experiment. Furthermore, Table 4 reports summary statistics of the socio-demographic characteristics that have been collected at the end of the experiment.

[Table 4 here]

As we have conducted our experiment with students from economics departments at different universities there is only little variation with respect to age and the majority of participants are male students. Furthermore, the 7-point scales for family income ten years ago, expected income in ten years' time, and political orientation are each merged into three categories. The data in Table 4 shows that about 46 percent of the respondents declared that they grew up in a (rather) rich family. Even more remarkably, 78 percent expect to earn a high or very high income in the future. In fact, only 17 individuals assume to fall into a lower income category than their family. With respect to their political orientation, the students in the sample slightly tend to the left on average. 
To illustrate potential effects from individual and group-specific characteristics Table A4 in the Appendix presents the distribution of answers on the five rule-based loss allocations for different groups of individuals. We report corresponding Pearson chi-squared test statistics to evaluate the significance of respective overall differences. Furthermore, the multinomial logistic regression model reported in Table 5 enables us to investigate differences between different socio-demographic groups with respect to single rule-based solutions while controlling for other confounders.

In the following, we focus on the most remarkable results. We observe strong endowment effects which likely indicate self-interest motives. Participants with higher endowment of 15 or 20 Euros more often propose allocations in accordance with equal losses or proportionality. In contrast, individuals with lower endowment more regularly suggest allocations which completely exclude themselves from carrying any loss (i.e. CEA in the case of 10 Euros; $\alpha=$ $1 / 3$ in the case of 5 Euros). According to the $\chi^{2}$ test reported in Table A4 these differences are highly statistically significant ( $\mathrm{p}$-value $<0.001$ ). Furthermore, these observations are confirmed by the regression results.

From the regression coefficients it can also be seen that an equal allocation of losses is more often proposed in earlier rounds of the game $(\mathrm{p}=0.007)$ and by younger participants $(\mathrm{p}=0.041)$ if we control for endowment effects. Such equality ideas may turn out to be rather naïve after a few rounds. Also, older students seem to drift away from the idea of equal losses.

Furthermore, some gender differences appear with respect to the CEA solution. Women more often than men propose to completely exclude the two individuals with lower endowments from any losses $(\mathrm{p}=0.016)$. This observation is in line with many findings in the literature starting with Carol Gilligan's (1982) claim that women are more likely to follow a care perspective.

While the income of the family in which the participant grew up has no clear impact, the overall effect of future income expectations is strong (see $\chi^{2}$ test in Table A4; $=0.002$ ), although the group of those who assume to earn a low or middle income is rather small. If a person expects to belong to an upper income class in the future, the probability to propose a proportional split of losses decreases by 22.5 percent $(\mathrm{p}=0.031)$ while the probability of excluding one or even two group members from carrying any losses significantly increases by 22.1 percent $(\mathrm{p}=0.045)$ and 18.4 percent $(\mathrm{p}<0.001)$ respectively. Having controlled for endowment effects, this result may indicate a concern for poorer individuals.

Additionally, participants who indicate a political orientation to the right are much more likely to propose a solution close to our model with $\alpha=1 / 4(\mathrm{p}=0.038)$ while the probability of proposing an allocation in accordance with the model with $\alpha=1 / 3$ decreases by 32.3 percent $(\mathrm{p}=0.003)$ compared to left-oriented individuals. Maybe these differences, which are again confirmed by our $\chi^{2}$ test, reveal typical disparities associated with different political convictions.

Finally, there are also some strong local differences. However, we suppose that the different groups are quite heterogeneous so that further interpretations may not be valid. Nevertheless, 
it seems to be important to control for these place effects to get more reliable results for the other individual and group-specific characteristics.

In Subsection 4.1 and especially in Table 2, we reported that 9 out of 21 final solutions were closest to the CEA model. In some contrast, according to our multinomial logistic regression model in Table 5, only 14.5 percent of all proposals have been closest to the CEA model while the predicted probability of observing an allocation which is closest to our model with $\alpha$ $=1 / 3$ equals 46.9 percent. Hence, it appears that the different specifications of our model expressed by the $\alpha$-values quite comprehensively explain the different proposals on the way to a commonly accepted allocation of losses. But in the specific setting of the experiment with veto power for all group members, participants may at some point realize that an agreement would be more easily achieved if the two lower endowed individuals were fully exempted from any losses.

\section{Discussion and conclusion}

Given an allocation of unequal initial endowments, how should a loss be shared among those who are concerned? The paper started out with the axiomatic characterization of a simple model which proposes a possible solution to this problem. Our model uses an equal share of the loss and the average endowment of those involved as reference points. In experiments at four universities we were interested to see how our model would fare against other rules, in particular against a scheme that was proposed in cases of bankruptcy and bequest, namely the constrained equal awards rule CEA. In our experimental set-up where within each group of players with an unequal initial endowment, the proposer in each round of bargaining was not known to the other group members, CEA and our model were implicitly chosen in roughly equal numbers. Implicit means that the students who played this game had been introduced neither to these models nor to any other alternative decision modes. In sharp contrast to this observation, our model with an $\alpha$-value of $1 / 3$ was closest to almost every second proposal.

We already mentioned that our concept of closeness is somewhat arbitrary, admittedly lacking a more basic foundation. However, a small deviation from a model's prescribed values seems to support that model's predictability. It should be obvious that one cannot expect students to pick distributions of losses that exactly correspond to a model's prescription, all the more because our model is continuous in relation to different alpha values. Therefore, the consideration of small Euclidean distances appears to us to make a lot of sense.

In addition to these findings, we observed quite a few cases where the final solution to the burden sharing problem was not achieved by mutual agreement but was, after a deadline of twenty minutes of bargaining, determined randomly. In eight of these ten cases, there had been proposals that were aimed at distributing the total loss very unevenly. One of these cases was described in some detail in Subsection 4.2. These proposals may have poisoned the atmosphere among the agents. In such cases, it seems to be a hopeless undertaking to describe proposals and counter-proposals by a model of rational decision making. Anger and frustration may have been the dominating factors in such situations. 
This last observation leads to the question whether a final solution, either via unanimous agreement or determined randomly, can be better understood by focusing on the whole sequence of proposals over time. A closer analysis of this procedural aspect appears worth doing but would need more data than obtained so far.

We find two other aspects particularly worth focusing on, and these will be the object of future experiments:

(a) How would a situation influence the bargaining over losses in which the initial endowment of each player is determined by the player's success in a knowledge quiz? Would relative success of a player be honored by the other members of this group? Would nasty proposals then occur much less frequently than in the experiments documented in this paper?

(b) How and in what way would the bargaining procedure change if the endowment status of the proposer of a particular loss division were known to all the other players in his or her group? Would such information lead to more decency and collaboration so that the number of random solutions would considerably go down? 


\section{References}

Aczél, János. Lectures on functional equations and their applications. New York: Academic Press, 1966.

Aumann, Robert J and Maschler, Michael. "Game Theoretic Analysis of a Bankruptcy Problem from the Talmud." Journal of Economic Theory, 1985, 36, pp. 195-213.

Berger, Roger; Rauhut, Heiko; Prade, Sandra and Helbing, Dirk. "Bargaining over Waiting Time in Ultimatum Game Experiments.” Social Science Research, 2012, 41, pp. 372-379.

Borges, Bernhard F. J. and Knetsch, Jack L. "Valuation of Gains and Losses, Fairness and Negotiation Outcomes.” International Journal of Social Economics, 1997, 24, pp. 265-281.

Bosmans, Kristof and Schokkaert, Erik. "Equality Preferences in the Claims Problem: A Questionnaire Study of Cuts in Earnings and Pensions." Social Choice and Welfare, 2009, 33, pp. 533-557.

Buchan, Nancy; Croson, Rachel; Johnson, Eric and Wu, George. "Gain and Loss Ultimatums." Experimental and Behavioural Economics, Advances in Applied Microeconomics, 2005, 13, pp. 1-23.

Gächter, Simon and Riedl, Arno. "Dividing Justly in Bargaining Problems with Claims: Normative Judgments and Actual Negotiations." Social Choice and Welfare, 2006, 27, pp. 571594.

Gaertner, Wulf and Schwettmann, Lars. "Burden Sharing in Deficit Countries: A Questionnaire-Experimental Investigation.” Journal of the Spanish Economic Association (SERIEs), forthcoming. DOI: 10.1007/s13209-016-0151-8.

Gilligan, Carol. In a different voice: psychology theory and women's development. Cambridge, Mass.: Harvard University Press, 1982.

Herrero, Carmen and Villar, Antonio. "The Three Musketeers: Four Classical Solutions to Bankruptcy Problems.” Mathematical Social Sciences, 2001, 42, pp.307-328.

Herrero, Carmen; Moreno-Ternero, Juan D. and Ponti, Giovanni. "On the Adjudication of Conflicting Claims: An Experimental Study." Social Choice and Welfare, 2010, 34, pp. 145179.

Kalai, Ehud and Smorodinsky, Meir. “Other Solutions to Nash's Bargaining Problem.” Econometrica, 1975, 43, pp. 513-518.

Maschler, Michael and Perles, Menahem A. "The Super-Additive Solution for the Nash Bargaining Game.” International Journal of Game Theory, 1981, 10, pp. 163-193.

Nash, John F. “The Bargaining Problem.” Econometrica, 1950, 18, pp. 155-162.

Roth, Alvin E. Axiomatic models of bargaining. Heidelberg, Berlin: Springer, 1979. 
Sheskin, David J. Handbook of parametric and nonparametric statistical procedures, 5 th ed. Boca Raton, FL: Chapman \& Hall, 2011.

Thomson, William. "Axiomatic and Game-Theoretic Analysis of Bankruptcy and Taxation Problems: A Survey.” Mathematical Social Sciences, 2003, 45, pp. 249-297.

Thomson, William. "A Characterization of a Family of Rules for the Adjudication of Conflicting Claims." Games and Economic Behavior, 2013, 82, pp. 157-168.

Van Dijk, Erik; Engelen, Mirjam; Van Leeuwen, Esther; Monden, Laura and Sluijter, Erik. "Distributive Justice and the Allocation of Costs, Losses, and Profits." Social Justice Research, 1999, 12, pp. 5-18.

Zhou, Xiaolin and Wu, Yan. "Sharing Losses and Sharing Gains: Increased Demand for Fairness under Adversity.” Journal of Experimental Social Psychology, 2011, 47, pp. 582-588. 
Table 1: Overview of sessions

\begin{tabular}{cccc}
\hline Place & Date & Equal Endowment & Unequal Endowment \\
\hline Berlin & January 28, 2016 & 3 groups & 4 groups \\
Galway & November 26, 2015 & --- & 7 groups \\
Halle & April 30, 2015 & 2 groups & 6 groups \\
Halle & June 23, 2016 & --- & 7 groups \\
Madrid & October 21, 2015 & --- & 6 groups \\
\hline Total number of individuals & 20 & 120 \\
\hline
\end{tabular}


Table 2: Final allocations of losses in the case of unequal endowments

\begin{tabular}{|c|c|c|c|c|c|c|}
\hline Place & Group & $\begin{array}{c}\text { Final losses } \\
\left(\mathrm{L}_{5}, \mathrm{~L}_{10}, \mathrm{~L}_{15}, \mathrm{~L}_{20}\right)\end{array}$ & $\begin{array}{l}\text { Final } \\
\text { round }\end{array}$ & $\begin{array}{l}\text { Proposer } \\
\left(\mathrm{P}_{\mathrm{i}}\right)\end{array}$ & $\begin{array}{l}\text { Closest } \\
\text { model }\end{array}$ & $\begin{array}{c}\text { Euclidean } \\
\text { distance }\end{array}$ \\
\hline \multirow[t]{4}{*}{ Berlin } & 1 & Random & 21 & & & \\
\hline & 2 & Random & 23 & & & \\
\hline & 3 & $(0,2,3,5)$ & 1 & $\mathrm{P}_{15}$ & $\alpha=1 / 3$ & 0.4714 \\
\hline & 4 & $(0,0,2.5,7.5)$ & 1 & $\mathrm{P}_{5}$ & CEA & 0.0000 \\
\hline \multirow[t]{7}{*}{ Galway } & 1 & $(1,1,3,5)$ & 3 & $\mathrm{P}_{15}$ & $\alpha=1 / 4$ & 1.1456 \\
\hline & 2 & Random & 19 & & & \\
\hline & 3 & $(0,1,4,5)$ & 7 & $\mathrm{P}_{10}$ & $\alpha=1 / 3$ & 0.9428 \\
\hline & 4 & $(0,2,3,5)$ & 5 & $\mathrm{P}_{5}$ & $\alpha=1 / 3$ & 0.4714 \\
\hline & 5 & $(0,0,2.5,7.5)$ & 7 & $\mathrm{P}_{20}$ & CEA & 0.0000 \\
\hline & 6 & $(1,2,3,4)$ & 1 & $\mathrm{P}_{5}$ & $\alpha=1 / 5$ & 0.0000 \\
\hline & 7 & Random & 14 & & & \\
\hline \multirow[t]{6}{*}{ Halle 2015} & 1 & $(0,0,5,5)$ & 9 & $\mathrm{P}_{15}$ & $\alpha=1 / 3$ & 2.3570 \\
\hline & 2 & $(4,2,2,2)$ & 1 & $\mathrm{P}_{5}$ & $\alpha=0$ & 1.7321 \\
\hline & 3 & $(0,1,2,7)$ & 16 & $P_{10}$ & CEA & 1.2247 \\
\hline & 4 & $(0.5,2,3,4.5)$ & 4 & $\mathrm{P}_{20}$ & $\alpha=1 / 4$ & 0.2500 \\
\hline & 5 & Random & 12 & & & \\
\hline & 6 & $(0,2,3,5)$ & 1 & $\mathrm{P}_{5}$ & $\alpha=1 / 3$ & 0.4714 \\
\hline \multirow[t]{7}{*}{ Halle 2016} & 1 & $(0.25,0.75,2.5,6.5)$ & 7 & $\mathrm{P}_{15}$ & CEA & 1.2748 \\
\hline & 2 & Random & 11 & & & \\
\hline & 3 & $(0,1,3,6)$ & 2 & $\mathrm{P}_{20}$ & $\alpha=1 / 3$ & 1.2472 \\
\hline & 4 & $(0,0,3,7)$ & 2 & $\mathrm{P}_{10}$ & CEA & 0.7071 \\
\hline & 5 & $(0,0,3,7)$ & 3 & $\mathrm{P}_{10}$ & CEA & 0.7071 \\
\hline & 6 & $(0,0.75,3,6.25)$ & 16 & $\mathrm{P}_{20}$ & CEA & 1.5411 \\
\hline & 7 & Random & 12 & & & \\
\hline \multirow[t]{6}{*}{ Madrid } & 1 & $(2,4,2,2)$ & 1 & $P_{10}$ & $\alpha=0$ & 1.7321 \\
\hline & 2 & Random & 15 & & & \\
\hline & 3 & $(1,2,3,4)$ & 4 & $\mathrm{P}_{20}$ & $\alpha=1 / 5$ & 0.0000 \\
\hline & 4 & $(0,0,2.5,7.5)$ & 5 & $\mathrm{P}_{5}$ & CEA & 0.0000 \\
\hline & 5 & $(0,0,3,7)$ & 2 & $\mathrm{P}_{10}$ & CEA & 0.7071 \\
\hline & 6 & Random & 17 & & & \\
\hline
\end{tabular}

Note: $\mathrm{L}_{\mathrm{i}}$ denotes the loss in Euro allocated to players with endowment level $\mathrm{i}$ and is a short form of $f_{i}(\xi)$ in the theoretical model. 
Table 3: Ranking of theoretical solutions in relation to actual proposals excluding of antagonistic proposals: Absolute frequencies and mean Euclidean distance $(n=214)$

\begin{tabular}{|c|c|c|c|c|c|}
\hline & $\begin{array}{l}\quad \alpha=0: \\
\text { Equal losses }\end{array}$ & $\alpha=1 / 3$ & $\alpha=1 / 4$ & $\begin{array}{c}\alpha=1 / 5: \\
\text { Proportional }\end{array}$ & CEA \\
\hline $\begin{array}{l}\mathbf{1}^{\text {st }} \text { rank: } \\
\text { Frequencies } \\
\text { Mean Euclidean } \\
\text { distance (S.D.) }\end{array}$ & $\begin{array}{c}27 \\
2.2555 \\
(1.8136)\end{array}$ & $\begin{array}{c}72 \\
1.0824 \\
(0.6202)\end{array}$ & $\begin{array}{c}28 \\
1.0133 \\
(0.6812)\end{array}$ & $\begin{array}{c}40 \\
0.2872 \\
(0.8409)\end{array}$ & $\begin{array}{c}47 \\
0.8045 \\
(0.5556)\end{array}$ \\
\hline $\begin{array}{l}2^{\text {nd }} \text { rank: } \\
\text { Frequencies } \\
\text { Mean Euclidean } \\
\text { distance (S.D.) }\end{array}$ & 0 & $\begin{array}{c}\quad 55 \\
2.5933 \\
(0.9061)\end{array}$ & $\begin{array}{c}93 \\
1.1377 \\
(0.7531)\end{array}$ & $\begin{array}{c}47 \\
2.7717 \\
(1.7975)\end{array}$ & $\begin{array}{c}19 \\
1.9240 \\
(0.1269)\end{array}$ \\
\hline $\begin{array}{l}\text { 3rd }^{\text {rd }} \text { Fank: } \\
\text { Frequencies } \\
\text { Mean Euclidean } \\
\text { distance (S.D.) }\end{array}$ & $\begin{array}{c}7 \\
2.3684 \\
(1.3376)\end{array}$ & $\begin{array}{c}\quad 53 \\
1.5068 \\
(0.3718)\end{array}$ & $\begin{array}{c}93 \\
3.4638 \\
(1.2036)\end{array}$ & $\begin{array}{c}58 \\
1.7470 \\
(0.5889)\end{array}$ & $\begin{array}{c}4 \\
2.3847 \\
(0.3708)\end{array}$ \\
\hline $\begin{array}{l}\mathbf{4}^{\text {th }} \text { rank: } \\
\text { Frequencies } \\
\text { Mean Euclidean } \\
\text { distance (S.D.) }\end{array}$ & $\begin{array}{c}61 \\
2.6452 \\
(0.4994)\end{array}$ & $\begin{array}{c}32 \\
4.5631 \\
(1.7524)\end{array}$ & 0 & $\begin{array}{c}69 \\
3.4868 \\
(0.8326)\end{array}$ & $\begin{array}{c}55 \\
3.2445 \\
(0.6232)\end{array}$ \\
\hline $\begin{array}{l}\mathbf{5}^{\text {th }} \text { rank: } \\
\text { Frequencies } \\
\text { Mean Euclidean } \\
\text { distance (S.D.) }\end{array}$ & $\begin{array}{c}119 \\
4.8229 \\
(1.0093)\end{array}$ & $\begin{array}{c}2 \\
6.2361 \\
(0.0000)\end{array}$ & 0 & 0 & $\begin{array}{c}89 \\
5.1272 \\
(1.6922)\end{array}$ \\
\hline Mean Rank & $\begin{array}{c}4.14 \\
(1.3082)\end{array}$ & $\begin{array}{c}2.24 \\
(1.1024)\end{array}$ & $\begin{array}{c}2.30 \\
(0.6895)\end{array}$ & $\begin{array}{c}2.73 \\
(1.1054)\end{array}$ & $\begin{array}{c}3.56 \\
(1.6079)\end{array}$ \\
\hline $\begin{array}{l}\text { Euclidean dis- } \\
\text { tance: Total } \\
\text { sample }\end{array}$ & $\begin{array}{c}3.7979 \\
(1.5565)\end{array}$ & $\begin{array}{c}2.1445 \\
(1.5452)\end{array}$ & $\begin{array}{c}2.1323 \\
(1.5166)\end{array}$ & $\begin{array}{c}2.2602 \\
(1.5777)\end{array}$ & $\begin{array}{c}3.3583 \\
(2.0743)\end{array}$ \\
\hline
\end{tabular}

Note: Stated "Frequencies" indicate the number of observation for which the allocation proposed is first, second, third, fourth and fifth closest, respectively, to the corresponding rule based on the Euclidean distance. "Mean Euclidean distance" corresponds to the subsample indicated in this cell. Standard deviations (S.D.) are given in brackets. In a few cases, the Euclidean distance between a proposed loss vector and two different rule-based vectors is identical. Hence, the horizontal sum of frequencies in the table does not always add up to 214 . Antagonistic proposals are omitted. 
Table 4: Socio-demographic characteristics

\begin{tabular}{lllll}
\hline & Mean & Std. Dev. & Min & Max \\
\hline Age (in years) & 22.91 & 3.669 & 18 & 37 \\
Sex (0=female, 1=male) & 0.650 & & 0 & 1 \\
Family income (1=very poor, 7 = very rich) & 4.275 & 1.130 & 1 & 7 \\
$\quad$ Low (answers 1-3) & 0.233 & & 0 & 1 \\
Middle (answer 4) & 0.308 & & 0 & 1 \\
High (answers 5-7) & 0.458 & & 0 & 1 \\
Future income (1=very low, 7 = very high) & 5.142 & 1.048 & 2 & 7 \\
Low (answers 1-3) & 0.075 & & 0 & 1 \\
Middle (answer 4) & 0.142 & & 0 & 1 \\
High (answers 5-7) & 0.783 & & 0 & 1 \\
Political orientation (1=left, 7 = right) & 3.750 & 1.272 & 1 & 7 \\
Left (answers 1-3) & 0.375 & & 0 & 1 \\
Middle (answer 4) & 0.417 & & 0 & 1 \\
Right (answers 5-7) & 0.208 & & 0 & 1 \\
\hline
\end{tabular}

Number of observations: $n=120$. Only groups with unequal endowments are included. 
Table 5: Multinomial logistic regression model for individual proposals

\begin{tabular}{|c|c|c|c|c|c|}
\hline & \multicolumn{5}{|c|}{ First ranked theoretical solution $\left(n=214\right.$, Pseudo $\left.R^{2}=0.242\right)$} \\
\hline & $\begin{array}{l}\alpha=0: \\
\text { Equal losses } \\
\text { dy/dx (SE) }\end{array}$ & $\begin{array}{l}\alpha=1 / 5: \\
\text { Proportional } \\
\mathrm{dy} / \mathrm{dx}(\mathrm{SE})\end{array}$ & $\begin{array}{r}\alpha=1 / 4 \\
\mathrm{dy} / \mathrm{dx}(\mathrm{SE})\end{array}$ & $\begin{array}{r}\alpha=1 / 3 \\
\mathrm{dy} / \mathrm{dx}(\mathrm{SE})\end{array}$ & $\begin{array}{l}\text { CEA } \\
\mathrm{dy} / \mathrm{dx}(\mathrm{SE})\end{array}$ \\
\hline $\begin{array}{l}\text { Endowment }(5,10 \text {, } \\
15, \text { or } 20 \text { Euros })\end{array}$ & $\begin{array}{l}0.012 * * * \\
(0.004)\end{array}$ & $\begin{array}{l}0.029 * * * \\
(0.006)\end{array}$ & $\begin{array}{l}-0.003 \\
(0.005)\end{array}$ & $\begin{array}{l}-0.022 * * * \\
(0.008)\end{array}$ & $\begin{array}{l}-0.017 * * * \\
(0.005)\end{array}$ \\
\hline Round & $\begin{array}{l}-0.011 * * * \\
(0.004)\end{array}$ & $\begin{array}{l}-0.004 \\
(0.004)\end{array}$ & $\begin{array}{l}0.005 \\
(0.006)\end{array}$ & $\begin{array}{l}0.007 \\
(0.009)\end{array}$ & $\begin{array}{l}0.003 \\
(0.005)\end{array}$ \\
\hline Age (in years) & $\begin{array}{l}-0.013 * * \\
(0.006)\end{array}$ & $\begin{array}{l}-0.001 \\
(0.009)\end{array}$ & $\begin{array}{l}-0.006 \\
(0.010)\end{array}$ & $\begin{array}{l}-0.001 \\
(0.014)\end{array}$ & $\begin{array}{l}0.021 * \\
(0.012)\end{array}$ \\
\hline $\begin{array}{l}\text { Sex }(0=\text { female, } \\
1=\text { male })\end{array}$ & $\begin{array}{l}0.073 * \\
(0.039)\end{array}$ & $\begin{array}{l}0.016 \\
(0.065)\end{array}$ & $\begin{array}{l}-0.043 \\
(0.062)\end{array}$ & $\begin{array}{l}0.099 \\
(0.104)\end{array}$ & $\begin{array}{l}-0.145^{* *} \\
(0.060)\end{array}$ \\
\hline \multicolumn{6}{|l|}{ Family income } \\
\hline Middle (answer 4) & $\begin{array}{l}-0.012 \\
(0.049)\end{array}$ & $\begin{array}{l}0.344^{*} \\
(0.177)\end{array}$ & $\begin{array}{l}-0.187 * * * \\
(0.070)\end{array}$ & $\begin{array}{l}-0.039 \\
(0.189)\end{array}$ & $\begin{array}{l}-0.106 \\
(0.070)\end{array}$ \\
\hline High (answers 5-7) & $\begin{array}{l}0.008 \\
(0.077)\end{array}$ & $\begin{array}{l}0.143 \\
(0.102)\end{array}$ & $\begin{array}{l}-0.099 * * \\
(0.048)\end{array}$ & $\begin{array}{l}0.012 \\
(0.143)\end{array}$ & $\begin{array}{l}-0.064 \\
(0.075)\end{array}$ \\
\hline \multicolumn{6}{|l|}{ Future income } \\
\hline High (answers 5-7) & $\begin{array}{l}-0.010 \\
(0.066)\end{array}$ & $\begin{array}{l}-0.225^{* *} \\
(0.105)\end{array}$ & $\begin{array}{l}-0.169 \\
(0.118)\end{array}$ & $\begin{array}{l}0.221 * * \\
(0.110)\end{array}$ & $\begin{array}{l}0.184 * * * \\
(0.051)\end{array}$ \\
\hline \multicolumn{6}{|l|}{ Political orientation } \\
\hline Middle (answer 4) & $\begin{array}{l}-0.126 * * \\
(0.057)\end{array}$ & $\begin{array}{l}-0.023 \\
(0.054)\end{array}$ & $\begin{array}{l}0.161 * \\
(0.092)\end{array}$ & $\begin{array}{l}-0.159 \\
(0.111)\end{array}$ & $\begin{array}{l}0.148 \\
(0.106)\end{array}$ \\
\hline Right (answers 5-7) & $\begin{array}{l}-0.013 \\
(0.045)\end{array}$ & $\begin{array}{l}-0.004 \\
(0.085)\end{array}$ & $\begin{array}{l}0.375 * * \\
(0.180)\end{array}$ & $\begin{array}{l}-0.323 * * * \\
(0.109)\end{array}$ & $\begin{array}{l}-0.035 \\
(0.082)\end{array}$ \\
\hline \multicolumn{6}{|l|}{ Places } \\
\hline Berlin & $\begin{array}{l}-0.035 \\
(0.053)\end{array}$ & $\begin{array}{l}-0.163 * * * \\
(0.060)\end{array}$ & $\begin{array}{l}-0.100 * \\
(0.060)\end{array}$ & $\begin{array}{l}0.251 \\
(0.171)\end{array}$ & $\begin{array}{l}0.048 \\
(0.111)\end{array}$ \\
\hline Galway & $\begin{array}{l}-0.070 * \\
(0.043)\end{array}$ & $\begin{array}{l}-0.178 * * * \\
(0.055)\end{array}$ & $\begin{array}{l}-0.085 \\
(0.052)\end{array}$ & $\begin{array}{l}0.403 * * * \\
(0.131)\end{array}$ & $\begin{array}{l}-0.068 \\
(0.073)\end{array}$ \\
\hline Halle 2016 & $\begin{array}{l}-0.120 * * * \\
(0.035)\end{array}$ & $\begin{array}{l}-0.262 * * * \\
(0.045)\end{array}$ & $\begin{array}{l}-0.102 * * * \\
(0.038)\end{array}$ & $\begin{array}{l}-0.001 \\
(0.185)\end{array}$ & $\begin{array}{l}0.484 * * * \\
(0.153)\end{array}$ \\
\hline Madrid & $\begin{array}{l}-0.080 * * \\
(0.039)\end{array}$ & $\begin{array}{l}-0.160 * * * \\
(0.049)\end{array}$ & $\begin{array}{l}-0.097 * * \\
(0.043)\end{array}$ & $\begin{array}{l}0.274 * \\
(0.163)\end{array}$ & $\begin{array}{l}0.062 \\
(0.119)\end{array}$ \\
\hline $\mathrm{y}=\operatorname{Pr}($ choice $)$ (predict) & 0.080 & 0.166 & 0.140 & 0.469 & 0.145 \\
\hline
\end{tabular}

Robust standard errors are clustered at the group level and reported in parentheses. For dummy variables dy/dx refers to a discrete change from 0 to 1 . Base case: female, family income: low (answers 13), future income: low or middle (answers 1-4), political orientation: left (answers 1-3), place: Halle 2015. Antagonistic proposals are omitted. Levels of significance: * 10\%, ** 5\%, *** $1 \%$. 


\section{APPENDICES}

\section{A.1 The Game Protocol}

\section{Experiment: Loss Distribution}

Welcome and thank you for participating in this experiment. Please read the instructions carefully. They are identical for all participants. The instructions are also made available to you in paper form. You are welcome to consult them at any time during the experiment.

- You are taking part in an experiment where, starting from an initial distribution of endowments in terms of real money, losses have to be shared.

- You will be assigned to a group of four. At no point in the experiment, your identity will be disclosed nor will the identities of your other group members be revealed.

- At the beginning of the experiment, an initial distribution of endowments will be determined and announced, specifying the amount of Euros that each member of your group receives.

[page break]

- Your group will have to share a total loss of 10 Euros that will have to be given back to the experimenter at the end of the experiment.

- One randomly chosen member of your group will make a first proposal of how to distribute the loss among the members of your group.

- This and every other proposal that may follow has to be made within two minutes.

- $\quad$ "Negative" losses are not acceptable nor are proposals for individual losses accepted that are higher than a person's initial endowment.

- This screenshot is an example for the input mask

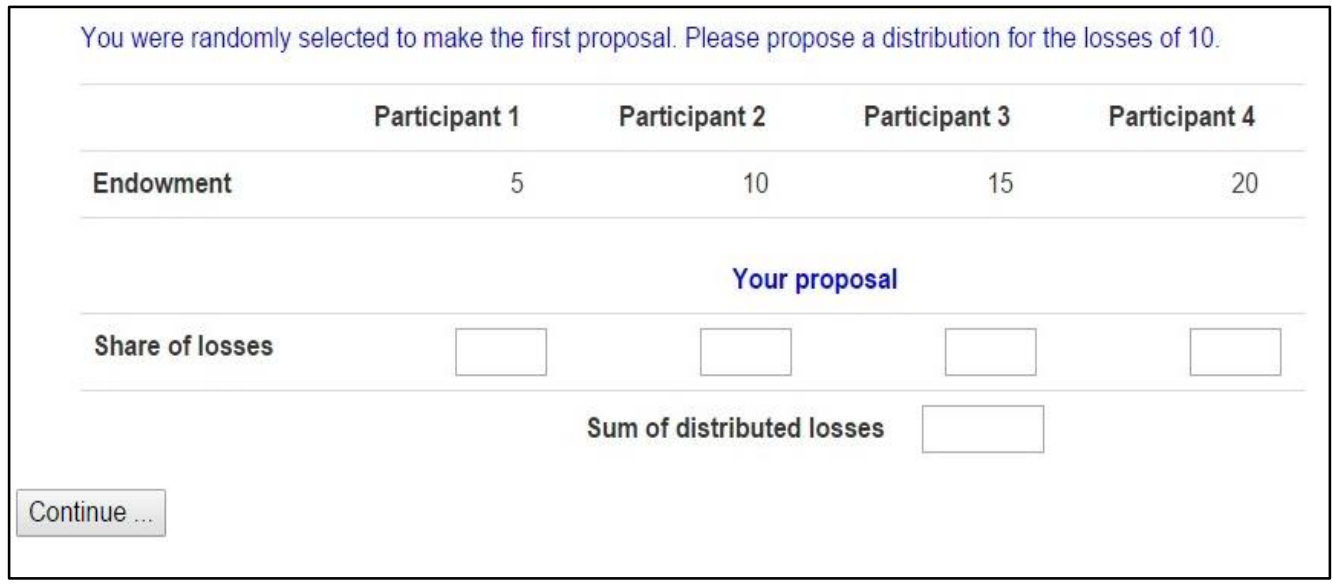

[page break]

- You are then asked to either accept or reject this first proposal. You have one minute to make your decision. Should you remain "silent", this will be defined as acceptance. 
- If the first proposal is accepted by all members of your group, the experiment is over and you will be paid your final net amount in cash at the day of the experiment. You will receive an envelope with your personal code number on it.

- Should there be no agreement, a second person in your group (also determined by chance, but, of course, different from the first person) will have to make a proposal of how to split up the loss.

- As long as no agreement on one proposal is reached among the group members, a new participant is chosen at random to propose a distribution of the loss of 10 Euros.

- While a new proposer is always chosen randomly, no person will be asked to make a second proposal before all other members have made at least one proposal (proposers are drawn from a hat without replacing).

- This last point equally applies in following rounds: Each participant will only get the chance to make his next proposal, after all players have also made at least one additional proposal.

[page break]

- If, at any point, one proposal receives unanimous agreement, the experiment is over and each participant receives his/her corresponding net payout as described above.

- There is a 20 minutes time limit for the experiment. After each round the remaining time is stated. Once the time has run out, the current proposal can still be made and the votes on it can still be taken.

- Please notice that if after these 20 minutes, none of the past proposals received unanimous support, the experiment is over.

- In this case, a random mechanism will pick one of the past proposals within your group as the final decision on the share of the loss of 10 Euros. Payment will be made as indicated above.

At the end of the experiment, you will be asked to answer a couple of questions which are also treated fully anonymously. Thank you for this as well and thank you again for participating in this experiment!

\section{A.2 The Complete Data Set}


Table A2: Overview of proposals and reactions

\begin{tabular}{|c|c|c|c|c|c|c|c|c|}
\hline \multirow[b]{2}{*}{ Round } & \multicolumn{4}{|c|}{ Proposal } & \multicolumn{4}{|c|}{ Reactions $(0=$ Accept, $1=$ Reject $)$} \\
\hline & $\mathrm{L}_{5}$ & $\mathrm{~L}_{10}$ & $\mathrm{~L}_{15}$ & $\mathrm{~L}_{20}$ & $\mathrm{P}_{5}$ & $\mathrm{P}_{10}$ & $P_{15}$ & $\mathrm{P}_{20}$ \\
\hline \multicolumn{9}{|c|}{ Berlin (Group 1) } \\
\hline 1 & 0 & 0 & 0 & 10 & 0 & $*$ & 0 & 1 \\
\hline 2 & 0 & 1 & 3 & 6 & $*$ & 1 & 0 & 1 \\
\hline 3 & 0 & 1 & 2 & 7 & 0 & 1 & $*$ & 1 \\
\hline 4 & 0 & 3 & 3 & 4 & 0 & 1 & 0 & $*$ \\
\hline 5 & 0 & 2 & 3 & 5 & $*$ & 1 & 0 & 0 \\
\hline 6 & 0 & 2 & 7 & 1 & 1 & 1 & 1 & $*$ \\
\hline 7 & 0 & 1 & 3.5 & 5.5 & 0 & 0 & $*$ & 1 \\
\hline 8 & 5 & 0 & 0 & 5 & 1 & $*$ & 1 & 1 \\
\hline 9 & 0 & 0 & 3.5 & 6.5 & 0 & 0 & $*$ & 1 \\
\hline 10 & 0 & 0 & 3 & 7 & 0 & $*$ & 0 & 1 \\
\hline 11 & $\mathbf{0}$ & 1 & 3 & 6 & $*$ & $\mathbf{0}$ & $\mathbf{0}$ & 1 \\
\hline 12 & 0 & 3 & 3 & 4 & 0 & 1 & 1 & $*$ \\
\hline 13 & 0 & 1.2 & 2.9 & 5.9 & $*$ & 1 & 0 & 1 \\
\hline 14 & 0 & 0.5 & 4 & 5.5 & 0 & 0 & $*$ & 1 \\
\hline 15 & 1 & 2 & 3 & 4 & 1 & 1 & 0 & $*$ \\
\hline 16 & 0 & 0.38 & 4.63 & 4.99 & 0 & $*$ & 1 & 1 \\
\hline 17 & 0 & 1.2 & 3.5 & 5.3 & $*$ & 1 & 0 & 1 \\
\hline 18 & 0 & 0.8 & 4 & 5.2 & 0 & 0 & $*$ & 1 \\
\hline 19 & 0.01 & 0.5 & 4.5 & 4.99 & 0 & $*$ & 1 & 1 \\
\hline 20 & 0 & 2 & 5 & 3 & 0 & 1 & 1 & $*$ \\
\hline 21 & 0 & 1 & 5 & 4 & 0 & 0 & 1 & $*$ \\
\hline
\end{tabular}

\begin{tabular}{ccccccccc}
\hline Berlin (Group 2) & & & & & & & \\
1 & 1 & 2 & 3 & 4 & 1 & 1 & $*$ & 1 \\
2 & 1 & 3 & 4 & 2 & 1 & 1 & 1 & $*$ \\
3 & 0 & 0 & 4 & 6 & $*$ & 0 & 1 & 1 \\
4 & 0 & 0 & 3 & 7 & 0 & $*$ & 1 & 1 \\
5 & 0 & 0 & 2 & 8 & $*$ & 0 & 1 & 1 \\
6 & 1 & 2.5 & 3 & 3.5 & 1 & 1 & 1 & $*$ \\
7 & 0 & 1 & 4 & 5 & 0 & $*$ & 1 & 1 \\
8 & 1 & 2 & 3 & 4 & 1 & 1 & $*$ & 1 \\
$\mathbf{9}$ & $\mathbf{5}$ & $\mathbf{5}$ & $\mathbf{0}$ & $\mathbf{0}$ & $\mathbf{1}$ & $\mathbf{1}$ & $\mathbf{1}$ & $*$ \\
10 & 0 & 0 & 0 & 10 & $*$ & 0 & 1 & 1 \\
11 & 0 & 1 & 3 & 6 & 0 & $*$ & 1 & 1 \\
12 & 1 & 2 & 3 & 4 & 1 & 1 & $*$ & 1 \\
13 & 1 & 2 & 3 & 4 & 1 & 1 & $*$ & 1 \\
14 & 0 & 10 & 0 & 0 & 0 & 1 & 1 & $*$ \\
15 & 0 & 0 & 3 & 7 & $*$ & 0 & 1 & 1 \\
16 & 0 & 0 & 2 & 8 & 0 & $*$ & 1 & 1 \\
17 & 0 & 1 & 2 & 7 & $*$ & 0 & 1 & 1 \\
18 & 0 & 1 & 3 & 6 & 0 & $*$ & 1 & 1 \\
19 & 1 & 2 & 3 & 4 & 1 & 1 & $*$ & 1 \\
20 & 0 & 10 & 0 & 0 & 0 & 1 & 1 & $*$ \\
21 & 0 & 1 & 2 & 7 & $*$ & 0 & 1 & 1 \\
22 & 1 & 2 & 3 & 4 & 1 & 1 & $*$ & 1 \\
23 & 0 & 10 & 0 & 0 & 0 & 1 & 1 & $*$ \\
& & & & & Timeout: Random solution round 9 \\
\hline
\end{tabular}


Table A2: Overview of proposals and reactions (continued)

\begin{tabular}{|c|c|c|c|c|c|c|c|c|}
\hline \multirow[b]{2}{*}{ Round } & \multicolumn{4}{|c|}{ Proposal } & \multicolumn{4}{|c|}{ Reactions $(0=$ Accept, $1=$ Reject $)$} \\
\hline & $\mathrm{L}_{5}$ & $\mathrm{~L}_{10}$ & $\mathrm{~L}_{15}$ & $\mathrm{~L}_{20}$ & $\mathrm{P}_{5}$ & $\mathrm{P}_{10}$ & $\overline{\mathrm{P}_{15}}$ & $\mathrm{P}_{20}$ \\
\hline \multicolumn{9}{|c|}{ Berlin (Group 3) } \\
\hline 1 & $\mathbf{0}$ & 2 & 3 & 5 & $\mathbf{0}$ & $\mathbf{0}$ & $*$ & $\mathbf{0}$ \\
\hline \multicolumn{9}{|c|}{ Berlin (Group 4) } \\
\hline 1 & $\mathbf{0}$ & $\mathbf{0}$ & 2.5 & 7.5 & $*$ & $\mathbf{0}$ & $\mathbf{0}$ & $\mathbf{0}$ \\
\hline \multicolumn{9}{|c|}{ Galway (Group 1) } \\
\hline 1 & 1 & 2 & 3 & 4 & 0 & $*$ & 1 & 0 \\
\hline 2 & 1 & 2 & 2 & 5 & $*$ & 1 & 0 & 0 \\
\hline 3 & 1 & 1 & 3 & 5 & $\mathbf{0}$ & $\mathbf{0}$ & $*$ & $\mathbf{0}$ \\
\hline \multicolumn{9}{|c|}{ Galway (Group 2) } \\
\hline 1 & 1 & 2 & 3 & 4 & $*$ & 1 & 0 & 0 \\
\hline 2 & 0 & 2 & 3 & 5 & 0 & 1 & $*$ & 1 \\
\hline 3 & 2 & 4 & 4 & 0 & 1 & 1 & 1 & $*$ \\
\hline 4 & 0.5 & 0.5 & 3 & 6 & 1 & $*$ & 0 & 1 \\
\hline 5 & 0.5 & 1 & 2.5 & 6 & 1 & 0 & $*$ & 1 \\
\hline 6 & 0 & 0 & 10 & 0 & 1 & 0 & 1 & $*$ \\
\hline 7 & 0 & 2 & 3 & 5 & $*$ & 1 & 0 & 1 \\
\hline 8 & 0 & $\mathbf{0}$ & 5 & 5 & $\mathbf{0}$ & $*$ & 0 & 1 \\
\hline 9 & 0 & 0 & 5 & 5 & 0 & $*$ & 0 & 1 \\
\hline 10 & 0 & 0 & 0 & 10 & 0 & 0 & $*$ & 1 \\
\hline 11 & 5 & 5 & 0 & 0 & 1 & 1 & 0 & $*$ \\
\hline 12 & 0 & 1 & 3 & 6 & $*$ & 0 & 0 & 1 \\
\hline 13 & 0 & 0 & 4.5 & 5.5 & 0 & $*$ & 0 & 1 \\
\hline 14 & 1 & 2 & 3 & 4 & 1 & 1 & $*$ & 0 \\
\hline 15 & 2.5 & 2.5 & 2.5 & 2.5 & 1 & 1 & 0 & $*$ \\
\hline 16 & 0 & 2 & 3 & 5 & $*$ & 1 & 0 & 1 \\
\hline 17 & 0 & 0 & 5 & 5 & 0 & 0 & $*$ & 1 \\
\hline 18 & 0 & 2 & 3.5 & 4.5 & $*$ & 1 & 0 & 1 \\
\hline 19 & 0 & 0 & 4 & 6 & 0 & $*$ & 0 & 1 \\
\hline \multicolumn{9}{|c|}{ Timeout: Random solution round 8} \\
\hline \multicolumn{9}{|c|}{ Galway (Group 3) } \\
\hline 1 & 3 & 3 & 1 & 3 & 1 & 1 & $*$ & 1 \\
\hline 2 & 1 & 2 & 3 & 4 & 1 & 1 & 1 & $*$ \\
\hline 3 & 1 & 1 & 4 & 4 & $*$ & 0 & 1 & 0 \\
\hline 4 & 0 & 0 & 3 & 7 & 0 & $*$ & 1 & 1 \\
\hline 5 & 2.5 & 2.5 & 2.5 & 2.5 & $*$ & 1 & 0 & 1 \\
\hline 6 & 0.5 & 1.5 & 3 & 5 & 1 & 1 & 0 & $*$ \\
\hline 7 & $\mathbf{0}$ & 1 & 4 & 5 & $\mathbf{0}$ & $*$ & 0 & 0 \\
\hline
\end{tabular}


Table A2: Overview of proposals and reactions (continued)

\begin{tabular}{|c|c|c|c|c|c|c|c|c|c|}
\hline \multirow[b]{2}{*}{ Round } & \multicolumn{4}{|c|}{ Proposal } & & \multicolumn{4}{|c|}{ Reactions $(0=$ Accept, $1=$ Reject $)$} \\
\hline & $\mathrm{L}_{5}$ & $\mathrm{~L}_{10}$ & $\mathrm{~L}_{15}$ & $\mathrm{~L}_{20}$ & & $\mathrm{P}_{5}$ & $\mathrm{P}_{10}$ & $\overline{\mathrm{P}_{15}}$ & $\mathrm{P}_{20}$ \\
\hline \multicolumn{10}{|c|}{ Galway (Group 4) } \\
\hline 1 & 3 & 3 & 1 & 3 & & 1 & 1 & $*$ & 0 \\
\hline 2 & 1 & 1 & 4 & 4 & & 1 & $*$ & 1 & 0 \\
\hline 3 & - & - & - & - & & $*$ & - & - & - \\
\hline 4 & 1 & 2 & 3 & 4 & & 1 & 0 & 0 & $*$ \\
\hline 5 & $\mathbf{0}$ & 2 & 3 & 5 & & $*$ & $\mathbf{0}$ & $\mathbf{0}$ & $\mathbf{0}$ \\
\hline \multicolumn{10}{|c|}{ Galway (Group 5) } \\
\hline 1 & 0 & 0 & 5 & 5 & & 1 & 1 & 1 & $*$ \\
\hline 2 & 0 & 2 & 3 & 5 & & $*$ & 1 & 0 & 0 \\
\hline 3 & 0 & 0 & 3 & 7 & & 0 & $*$ & 1 & 0 \\
\hline 4 & - & - & - & - & & - & - & $*$ & - \\
\hline 5 & 0 & 1.5 & 2.5 & 6 & & $*$ & 1 & 1 & 0 \\
\hline 6 & 0.2 & 1.8 & 3.2 & 4.8 & & 1 & 1 & $*$ & 0 \\
\hline 7 & $\mathbf{0}$ & $\mathbf{0}$ & 2.5 & 7.5 & & $\mathbf{0}$ & $\mathbf{0}$ & $\mathbf{0}$ & $*$ \\
\hline \multicolumn{10}{|c|}{ Galway (Group 6) } \\
\hline 1 & 1 & 2 & 3 & 4 & & $*$ & $\mathbf{0}$ & $\mathbf{0}$ & $\mathbf{0}$ \\
\hline \multicolumn{10}{|c|}{ Galway (Group 7) } \\
\hline 1 & 0 & 0 & 3 & 7 & & 0 & $*$ & 1 & 1 \\
\hline 2 & 0 & 1 & 4 & 5 & & $*$ & 0 & 1 & 0 \\
\hline 3 & 1 & 1 & 2 & 6 & & 1 & 0 & $*$ & 1 \\
\hline 4 & 1.5 & 2 & 3 & 3.5 & & 1 & 0 & 1 & $*$ \\
\hline 5 & 1.5 & 2 & 2.5 & 4 & & 1 & 0 & $*$ & 1 \\
\hline 6 & 5 & 0 & 2.5 & 2.5 & & 1 & $*$ & 0 & 1 \\
\hline 7 & 0 & 1.5 & 3 & 5.5 & & $*$ & 0 & 1 & 1 \\
\hline 8 & 1 & 2 & 3 & 4 & & 0 & $\mathbf{0}$ & 1 & $*$ \\
\hline 9 & 1 & 2 & 2.5 & 4.5 & & 1 & 0 & $*$ & 0 \\
\hline 10 & 0 & 2 & 3 & 5 & & $*$ & 0 & 1 & 1 \\
\hline 11 & 1 & 1.5 & 3 & 4.5 & & 1 & 0 & 1 & $*$ \\
\hline 12 & 0.5 & 2 & 3 & 4.5 & & 0 & $*$ & 1 & 0 \\
\hline 13 & 0.5 & 2 & 3 & 4.5 & & $*$ & 0 & 1 & 0 \\
\hline 14 & 0.7 & 2 & 2.3 & 5 & & 0 & 0 & $*$ & 1 \\
\hline \multicolumn{10}{|c|}{ Timeout: Random solution round } \\
\hline \multicolumn{10}{|c|}{ Halle 2015 (Group 1) } \\
\hline 1 & - & - & - & - & 1 & * & - & - & - \\
\hline 2 & - & - & - & - & 2 & - & $*$ & - & - \\
\hline 3 & 3 & 3 & 2 & 2 & & 0 & 1 & $*$ & 0 \\
\hline 4 & 1 & 2 & 3 & 4 & & 1 & 0 & 0 & $*$ \\
\hline 5 & 3 & 3 & 2 & 2 & & $*$ & 1 & 1 & 0 \\
\hline 6 & 2.5 & 2.5 & 2.5 & 2.5 & & 1 & 1 & 0 & $*$ \\
\hline 7 & 2.5 & 2.5 & 2.5 & 2.5 & & 1 & 0 & $*$ & 0 \\
\hline 8 & 1 & 2 & 3 & 4 & & 1 & $*$ & 0 & 0 \\
\hline 9 & $\mathbf{0}$ & $\mathbf{0}$ & 5 & 5 & & $\mathbf{0}$ & $\mathbf{0}$ & $*$ & 0 \\
\hline
\end{tabular}


Table A2: Overview of proposals and reactions (continued)

\begin{tabular}{|c|c|c|c|c|c|c|c|c|}
\hline \multirow[b]{2}{*}{ Round } & \multicolumn{4}{|c|}{ Proposal } & \multicolumn{4}{|c|}{ Reactions $(0=$ Accept, $1=$ Reject $)$} \\
\hline & $\mathrm{L}_{5}$ & $\mathrm{~L}_{10}$ & $\mathrm{~L}_{15}$ & $\mathrm{~L}_{20}$ & $\mathrm{P}_{5}$ & $\mathrm{P}_{10}$ & $\overline{P_{15}}$ & $\mathrm{P}_{20}$ \\
\hline \multicolumn{9}{|c|}{ Halle 2015 (Group 2) } \\
\hline 1 & 4 & 2 & 2 & 2 & $*$ & $\mathbf{0}$ & $\mathbf{0}$ & $\mathbf{0}$ \\
\hline \multicolumn{9}{|c|}{ Halle 2015 (Group 3) } \\
\hline 1 & 1 & 2 & 2 & 5 & 0 & 1 & $*$ & 1 \\
\hline 2 & 1 & 2 & 3 & 4 & 1 & 0 & 0 & $*$ \\
\hline 3 & 1 & 2 & 3 & 4 & $*$ & 1 & 0 & 0 \\
\hline 4 & 0.5 & 1.5 & 2.5 & 5.5 & 0 & * & 0 & 1 \\
\hline 5 & 0.5 & 1.5 & 3 & 5 & $*$ & 0 & 1 & 1 \\
\hline 6 & 1 & 2 & 3 & 4 & 1 & 1 & 1 & $*$ \\
\hline 7 & 0.5 & 1.75 & 2.75 & 5 & 0 & $*$ & 1 & 1 \\
\hline 8 & 0 & 0 & 0 & 10 & 0 & 0 & $*$ & 1 \\
\hline 9 & 0.5 & 1.5 & 3.5 & 4.5 & 1 & 0 & 1 & $*$ \\
\hline 10 & 0.5 & 0 & 0 & 10 & $*$ & 0 & 0 & 1 \\
\hline 11 & 0 & 1 & 2 & 7 & 0 & $*$ & 0 & 1 \\
\hline 12 & 0 & 0 & 0 & 10 & 0 & 0 & $*$ & 1 \\
\hline 13 & 0 & 0 & 0 & 10 & 0 & 0 & $*$ & 1 \\
\hline 14 & 0 & 2 & 3 & 5 & 0 & 1 & 1 & $*$ \\
\hline 15 & 0 & 0 & 0 & 10 & $*$ & 0 & 0 & 1 \\
\hline 16 & $\mathbf{0}$ & 1 & 2 & 7 & $\mathbf{0}$ & $*$ & $\mathbf{0}$ & $\mathbf{0}$ \\
\hline \multicolumn{9}{|c|}{ Halle 2015 (Group 4) } \\
\hline 1 & 1 & 2 & 3 & 4 & 1 & 0 & $*$ & 0 \\
\hline 2 & 0 & 2 & 3 & 5 & 0 & $*$ & 0 & 1 \\
\hline 3 & 0.25 & 2 & 3.25 & 4.5 & $*$ & 0 & 0 & 1 \\
\hline 4 & 0.5 & 2 & 3 & 4.5 & $\mathbf{0}$ & $\mathbf{0}$ & $\mathbf{0}$ & $*$ \\
\hline \multicolumn{9}{|c|}{ Halle 2015 (Group 5) } \\
\hline 1 & 3 & 3 & 2 & 2 & 1 & 1 & 0 & $*$ \\
\hline 2 & 1 & 2 & 3 & 4 & $*$ & 1 & 0 & 0 \\
\hline 3 & 0 & 0 & 3 & 7 & 0 & $*$ & 1 & 1 \\
\hline 4 & 1 & 2 & 3 & 4 & 1 & 1 & $*$ & $\mathbf{0}$ \\
\hline 5 & 0.5 & 2 & 3.5 & 4 & $*$ & 1 & 1 & 1 \\
\hline 6 & 5 & 3 & 1 & 1 & 1 & 1 & $*$ & 0 \\
\hline 7 & 1 & 2 & 3 & 4 & 1 & 1 & 0 & $*$ \\
\hline 8 & 0 & 0 & 2.5 & 7.5 & 0 & $*$ & 1 & 1 \\
\hline 9 & 5 & 0 & 0 & 5 & 1 & 1 & $*$ & 1 \\
\hline 10 & 0.75 & 2.25 & 3.25 & 3.75 & $*$ & 1 & 0 & 0 \\
\hline 11 & - & - & - & - & - & - & - & $*$ \\
\hline 12 & 0 & 0 & 1 & 9 & 0 & $*$ & 0 & 1 \\
\hline \multicolumn{9}{|c|}{ Timeout: Random solution round 4} \\
\hline \multicolumn{9}{|c|}{ Halle 2015 (Group 6) } \\
\hline 1 & $\mathbf{0}$ & 2 & 3 & 5 & $*$ & $\mathbf{0}$ & $\mathbf{0}$ & $\mathbf{0}$ \\
\hline
\end{tabular}


Table A2: Overview of proposals and reactions (continued)

\begin{tabular}{|c|c|c|c|c|c|c|c|c|}
\hline \multirow[b]{2}{*}{ Round } & \multicolumn{4}{|c|}{ Proposal } & \multicolumn{4}{|c|}{ Reactions $(0=$ Accept, $1=$ Reject $)$} \\
\hline & $\mathrm{L}_{5}$ & $\mathrm{~L}_{10}$ & $\mathrm{~L}_{15}$ & $\mathrm{~L}_{20}$ & $\mathrm{P}_{5}$ & $\mathrm{P}_{10}$ & $\mathrm{P}_{15}$ & $\mathrm{P}_{20}$ \\
\hline \multicolumn{9}{|c|}{ Halle 2016 (Group 1) } \\
\hline 1 & 0 & 0 & 2.5 & 7.5 & 0 & $*$ & 0 & 1 \\
\hline 2 & 0 & 0.5 & 3 & 6.5 & $*$ & 0 & 1 & 0 \\
\hline 3 & 0.75 & 1.75 & 2.5 & 5 & 0 & 1 & $*$ & 0 \\
\hline 4 & 1 & 1 & 2 & 6 & 1 & 1 & 0 & $*$ \\
\hline 5 & 0.25 & 0.75 & 3 & 6 & $*$ & 0 & 1 & 0 \\
\hline 6 & 0 & 1 & 3 & 6 & 0 & 1 & 1 & $*$ \\
\hline 7 & 0.25 & 0.75 & 2.5 & 6.5 & $\mathbf{0}$ & $\mathbf{0}$ & $*$ & $\mathbf{0}$ \\
\hline \multicolumn{9}{|c|}{ Halle 2016 (Group 2) } \\
\hline 1 & 0 & 0 & 3 & 7 & $*$ & 0 & 1 & 1 \\
\hline 2 & 0 & 1 & 4 & 5 & 0 & 1 & $*$ & 0 \\
\hline 3 & $\mathbf{0}$ & 1.5 & 3 & 5.5 & $\mathbf{0}$ & 1 & 1 & $*$ \\
\hline 4 & 0 & 0 & 2.5 & 7.5 & 0 & $*$ & 0 & 1 \\
\hline 5 & 0 & 1 & 2 & 7 & 0 & 1 & $*$ & 1 \\
\hline 6 & 0 & 4 & 6 & 0 & 1 & 1 & 1 & $*$ \\
\hline 7 & 0 & 1 & 3.5 & 5.5 & $*$ & 1 & 0 & 1 \\
\hline 8 & 0 & 0 & 0 & 10 & 0 & $*$ & 0 & 1 \\
\hline 9 & 0 & 0 & 3 & 7 & 0 & $*$ & 0 & 1 \\
\hline 10 & 0.01 & 0.24 & 2.5 & 7.25 & 0 & 0 & $*$ & 1 \\
\hline 11 & 1 & 4 & 5 & 0 & 1 & 1 & 1 & $*$ \\
\hline \multicolumn{9}{|c|}{ Timeout: Random solution round 3} \\
\hline \multicolumn{9}{|c|}{ Halle 2016 (Group 3) } \\
\hline 1 & 1 & 2 & 3 & 4 & 1 & 1 & * & 0 \\
\hline 2 & $\mathbf{0}$ & 1 & 3 & 6 & $\mathbf{0}$ & $\mathbf{0}$ & $\mathbf{0}$ & $*$ \\
\hline \multicolumn{9}{|c|}{ Halle 2016 (Group 4) } \\
\hline 1 & 5 & 1 & 1 & 3 & 1 & 1 & $*$ & 0 \\
\hline 2 & $\mathbf{0}$ & $\mathbf{0}$ & 3 & 7 & $\mathbf{0}$ & $*$ & $\mathbf{0}$ & $\mathbf{0}$ \\
\hline \multicolumn{9}{|c|}{ Halle 2016 (Group 5) } \\
\hline 1 & 0 & 2 & 3 & 5 & 0 & 1 & 0 & $*$ \\
\hline 2 & 0.5 & 2 & 3 & 4.5 & $*$ & 1 & 0 & 0 \\
\hline 3 & $\mathbf{0}$ & $\mathbf{0}$ & 3 & 7 & $\mathbf{0}$ & $*$ & $\mathbf{0}$ & $\mathbf{0}$ \\
\hline
\end{tabular}


Table A2: Overview of proposals and reactions (continued)

\begin{tabular}{|c|c|c|c|c|c|c|c|c|}
\hline \multirow[b]{2}{*}{ Round } & \multicolumn{4}{|c|}{ Proposal } & \multicolumn{4}{|c|}{ Reactions $(0=$ Accept, $1=$ Reject $)$} \\
\hline & $\mathrm{L}_{5}$ & $\mathrm{~L}_{10}$ & $\mathrm{~L}_{15}$ & $\mathrm{~L}_{20}$ & $\mathrm{P}_{5}$ & $\mathrm{P}_{10}$ & $\overline{\mathrm{P}_{15}}$ & $\mathrm{P}_{20}$ \\
\hline \multicolumn{9}{|c|}{ Halle 2016 (Group 6) } \\
\hline 1 & 0 & 2 & 3 & 5 & $*$ & 1 & 0 & 1 \\
\hline 2 & 0 & 0 & 0 & 10 & 0 & $*$ & 0 & 1 \\
\hline 3 & 1 & 2 & 3 & 4 & 0 & 1 & 0 & $*$ \\
\hline 4 & 0 & 0 & 2.5 & 7.5 & 0 & 0 & $*$ & 1 \\
\hline 5 & 0 & 1 & 4 & 5 & $*$ & 1 & 0 & 0 \\
\hline 6 & 0 & 0 & 10 & 0 & 0 & $*$ & 1 & 0 \\
\hline 7 & 0 & 2 & 3.25 & 4.75 & 0 & 1 & 0 & $*$ \\
\hline 8 & 0 & 2 & 3 & 5 & 0 & 1 & $*$ & 0 \\
\hline 9 & 0 & 2 & 4 & 4 & 0 & 1 & $*$ & 0 \\
\hline 10 & 0 & 0 & 0 & 10 & $*$ & 0 & 0 & 1 \\
\hline 11 & 0 & 2 & 2.75 & 5.25 & 0 & 1 & 0 & $*$ \\
\hline 12 & 0 & 0 & 3.5 & 6.5 & 0 & $*$ & 0 & 1 \\
\hline 13 & 0 & 0 & 0 & 10 & $*$ & 0 & 0 & 1 \\
\hline 14 & 1 & 2.5 & 3 & 3.5 & 0 & 1 & $*$ & 0 \\
\hline 15 & 0 & 0 & 3 & 7 & 0 & $*$ & 0 & 1 \\
\hline 16 & $\mathbf{0}$ & 0.75 & 3 & 6.25 & $\mathbf{0}$ & $\mathbf{0}$ & $\mathbf{0}$ & $*$ \\
\hline \multicolumn{9}{|c|}{ Halle 2016 (Group 7) } \\
\hline 1 & 0 & 0 & 3 & 7 & 1 & $*$ & 0 & 0 \\
\hline 2 & 0 & 10 & 0 & 0 & $*$ & 1 & 0 & 0 \\
\hline 3 & 0 & 1 & 2 & 7 & 1 & 0 & $*$ & 0 \\
\hline 4 & 0 & 1 & 3 & 6 & 1 & 0 & 1 & $*$ \\
\hline 5 & 0 & 0 & 2.5 & 7.5 & 1 & 0 & $*$ & 0 \\
\hline 6 & 0 & 0 & 2 & 8 & 1 & $*$ & 0 & 0 \\
\hline 7 & 0 & 0 & 0 & 10 & $*$ & 0 & 0 & 1 \\
\hline 8 & 0 & 0.5 & 1.5 & 8 & 1 & 0 & 0 & $*$ \\
\hline 9 & 0.5 & 0.5 & 2 & 7 & 1 & 0 & $*$ & 0 \\
\hline 10 & 0 & 2 & 5 & 3 & $*$ & 1 & 1 & 0 \\
\hline 11 & 0 & 0 & 1.5 & 8.5 & 1 & 0 & 0 & $*$ \\
\hline \multirow[t]{2}{*}{12} & 0 & 0 & 1 & 9 & 1 & $*$ & 0 & 0 \\
\hline & & & & & \multicolumn{4}{|c|}{ Timeout: Random solution round 9} \\
\hline \multicolumn{5}{|c|}{ Madrid (Group 1) } & & & & \\
\hline 1 & 2 & 4 & 2 & 2 & $\mathbf{0}$ & $*$ & $\mathbf{0}$ & $\mathbf{0}$ \\
\hline
\end{tabular}


Table A2: Overview of proposals and reactions (continued)

\begin{tabular}{|c|c|c|c|c|c|c|c|c|}
\hline \multirow[b]{2}{*}{ Round } & \multicolumn{4}{|c|}{ Proposal } & \multicolumn{4}{|c|}{ Reactions $(0=$ Accept, $1=$ Reject $)$} \\
\hline & $\mathrm{L}_{5}$ & $\mathrm{~L}_{10}$ & $\mathrm{~L}_{15}$ & $\mathrm{~L}_{20}$ & $\mathrm{P}_{5}$ & $\mathrm{P}_{10}$ & $\overline{P_{15}}$ & $\mathrm{P}_{20}$ \\
\hline \multicolumn{9}{|c|}{ Madrid (Group 2) } \\
\hline 1 & 0 & 1 & 3 & 6 & $*$ & 1 & 1 & 1 \\
\hline 2 & 3 & 3 & 2 & 2 & 1 & 1 & $*$ & 0 \\
\hline 3 & 2 & 3 & 3 & 2 & 1 & 1 & 1 & $*$ \\
\hline 4 & 0 & 2 & 3 & 5 & 0 & $*$ & 1 & 0 \\
\hline 5 & 2.5 & 2.5 & 2.5 & 2.5 & 1 & 1 & $*$ & 0 \\
\hline 6 & 1.5 & 1.5 & 3.5 & 3.5 & 1 & 1 & 1 & $*$ \\
\hline 7 & 1 & 2 & 3 & 4 & $*$ & 1 & 1 & 0 \\
\hline 8 & 0.75 & 2 & 3 & 4.25 & 0 & $*$ & 1 & 0 \\
\hline 9 & 0 & 0 & 0 & 10 & 1 & $*$ & 0 & 1 \\
\hline 10 & 1.5 & 1.5 & 1 & 6 & 1 & 1 & $*$ & 1 \\
\hline 11 & 0 & 1.5 & 3.5 & 5 & 0 & 1 & 1 & $*$ \\
\hline 12 & 0 & 2 & 3 & 5 & $*$ & 1 & 1 & 0 \\
\hline 13 & 0.75 & 2 & 3 & 4.25 & $\mathbf{0}$ & $*$ & 1 & $\mathbf{0}$ \\
\hline 14 & 5 & 3 & 1 & 1 & 1 & 1 & $*$ & 1 \\
\hline \multirow[t]{2}{*}{15} & 1.5 & 1.5 & 3.5 & 3.5 & 1 & 1 & 1 & $*$ \\
\hline & & & & & \multicolumn{4}{|c|}{ Timeout: Random solution round 13} \\
\hline \multicolumn{9}{|c|}{ Madrid (Group 3) } \\
\hline 1 & 1 & 2 & 3 & 4 & 1 & 1 & $*$ & 0 \\
\hline 2 & 3 & 2.5 & 2.25 & 2.25 & 1 & $*$ & 0 & 0 \\
\hline 3 & 0 & 2 & 3 & 5 & $*$ & 1 & 0 & 0 \\
\hline 4 & 1 & 2 & 3 & 4 & $\mathbf{0}$ & $\mathbf{0}$ & $\mathbf{0}$ & $*$ \\
\hline \multicolumn{9}{|c|}{ Madrid (Group 4) } \\
\hline 1 & 0 & 10 & 0 & 0 & 1 & 1 & 0 & * \\
\hline 2 & 0 & 0 & 0 & 10 & $*$ & 1 & 0 & 0 \\
\hline 3 & 0 & 0 & 3 & 7 & 0 & $*$ & 0 & 1 \\
\hline 4 & 0 & 2.5 & 2.5 & 5 & 1 & 1 & $*$ & 0 \\
\hline 5 & $\mathbf{0}$ & $\mathbf{0}$ & 2.5 & 7.5 & $*$ & $\mathbf{0}$ & $\mathbf{0}$ & $\mathbf{0}$ \\
\hline \multicolumn{9}{|c|}{ Madrid (Group 5) } \\
\hline 1 & 0 & 2 & 3 & 5 & $*$ & 1 & 0 & 0 \\
\hline 2 & $\mathbf{0}$ & $\mathbf{0}$ & 3 & 7 & $\mathbf{0}$ & $*$ & $\mathbf{0}$ & $\mathbf{0}$ \\
\hline
\end{tabular}


Table A2: Overview of proposals and reactions (continued)

\begin{tabular}{|c|c|c|c|c|c|c|c|c|}
\hline \multirow[b]{2}{*}{ Round } & \multicolumn{4}{|c|}{ Proposal } & \multicolumn{4}{|c|}{ Reactions $(0=$ Accept, $1=$ Reject $)$} \\
\hline & $\mathrm{L}_{5}$ & $\mathrm{~L}_{10}$ & $\mathrm{~L}_{15}$ & $\mathrm{~L}_{20}$ & $\mathrm{P}_{5}$ & $\mathrm{P}_{10}$ & $\mathrm{P}_{15}$ & $\mathrm{P}_{20}$ \\
\hline \multicolumn{9}{|c|}{ Madrid (Group 6) } \\
\hline 1 & 0 & 0 & 0 & 10 & 0 & $*$ & 1 & 1 \\
\hline 2 & 1 & 1.5 & 2.5 & 5 & $*$ & 1 & 0 & 0 \\
\hline 3 & 1.25 & 2 & 2.75 & 4 & 1 & 1 & $*$ & 0 \\
\hline 4 & 0 & 1 & 4 & 5 & 0 & 1 & 1 & $*$ \\
\hline 5 & 0.75 & 1.5 & 2.75 & 5 & 1 & 1 & * & 0 \\
\hline 6 & 0 & 0 & 2.5 & 7.5 & 0 & $*$ & 1 & 1 \\
\hline 7 & 0 & 1 & 3 & 6 & $*$ & 1 & 1 & 0 \\
\hline 8 & 0 & 0 & 4 & 6 & 0 & 0 & 1 & $*$ \\
\hline 9 & 1 & 2 & 3 & 4 & 1 & 1 & $*$ & 0 \\
\hline 10 & 0 & 2 & 3 & 5 & $*$ & 1 & 0 & 0 \\
\hline 11 & 0 & 1 & 3 & 6 & 0 & 1 & 0 & $*$ \\
\hline 12 & 0 & 0 & 2.5 & 7.5 & 0 & $*$ & 1 & 1 \\
\hline 13 & 0 & 1 & 4 & 5 & $*$ & 1 & 1 & 0 \\
\hline 14 & 1 & 2 & 3 & 4 & 1 & 1 & $*$ & 0 \\
\hline 15 & 0 & 0 & 3.5 & 6.5 & 0 & $*$ & 1 & 1 \\
\hline 16 & 0 & 2 & 4 & 4 & $\mathbf{0}$ & 1 & 1 & $*$ \\
\hline \multirow[t]{2}{*}{17} & 0 & 2.5 & 3.5 & 4 & 0 & 1 & 0 & $*$ \\
\hline & & & & & \multicolumn{4}{|c|}{ Timeout: Random solution round 16} \\
\hline
\end{tabular}

Note: $\mathrm{L}_{\mathrm{i}}$ denotes the loss in Euro allocated to players with endowment level $\mathrm{i}$ and is short for what we denoted as $f_{i}(\xi)$ in the theoretical model. $\mathrm{P}_{\mathrm{i}}$ reflects the reactions of corresponding players. Here, a $*$ designates the proposer. Random or accepted solutions are in bold numbers. A “-“ denotes rounds in which a potential proposer abstains from making a proposal within the time limit. 
Table A3: Antagonistic proposals

\begin{tabular}{|c|c|c|c|c|c|}
\hline Place & Group & $\begin{array}{c}\text { Proposal } \\
\left(\mathrm{L}_{5}, \mathrm{~L}_{10}, \mathrm{~L}_{15}, \mathrm{~L}_{20}\right)\end{array}$ & Round & $\begin{array}{l}\text { Proposer } \\
\left(\mathrm{P}_{\mathrm{i}}\right)\end{array}$ & $\begin{array}{c}\text { Final solution } \\
\left(\mathrm{L}_{5}, \mathrm{~L}_{10}, \mathrm{~L}_{15}, \mathrm{~L}_{20}\right)\end{array}$ \\
\hline \multirow[t]{5}{*}{ Berlin } & 1 & $(0,0,0,10)$ & 1 & $\mathrm{P}_{10}$ & Random: $(0,1,3,6)$ \\
\hline & 2 & $(0,0,0,10)$ & 10 & $\mathrm{P}_{5}$ & \\
\hline & 2 & $(0,10,0,0)$ & 14 & $\mathrm{P}_{20}$ & \\
\hline & 2 & $(0,10,0,0)$ & 20 & $\mathrm{P}_{20}$ & \\
\hline & 2 & $(0,10,0,0)$ & 23 & $\mathrm{P}_{20}$ & Random: $(5,5,0,0)$ \\
\hline \multirow[t]{2}{*}{ Galway } & 2 & $(0,0,10,0)$ & 6 & $\mathrm{P}_{20}$ & \\
\hline & 2 & $(0,0,0,10)$ & 10 & $\mathrm{P}_{15}$ & Random: $(0,0,5,5)$ \\
\hline \multirow[t]{5}{*}{ Halle 2015} & 3 & $(0,0,0,10)$ & 8 & $\mathrm{P}_{15}$ & \\
\hline & 3 & $(0,0,0,10)$ & 10 & $\mathrm{P}_{5}$ & \\
\hline & 3 & $(0,0,0,10)$ & 12 & $\mathrm{P}_{15}$ & \\
\hline & 3 & $(0,0,0,10)$ & 13 & $\mathrm{P}_{15}$ & \\
\hline & 3 & $(0,0,0,10)$ & 15 & $\mathrm{P}_{5}$ & Random: $(1,2,3,4)$ \\
\hline \multirow[t]{7}{*}{ Halle 2016} & 2 & $(0,0,0,10)$ & 8 & $\mathrm{P}_{10}$ & Random: $(0,1.5,3,5.5)$ \\
\hline & 6 & $(0,0,0,10)$ & 2 & $\mathrm{P}_{10}$ & \\
\hline & 6 & $(0,0,10,0)$ & 6 & $\mathrm{P}_{10}$ & \\
\hline & 6 & $(0,0,0,10)$ & 10 & $\mathrm{P}_{5}$ & \\
\hline & 6 & $(0,0,0,10)$ & 13 & $\mathrm{P}_{5}$ & Accepted: $(0,0.75,3,6.25)$ \\
\hline & 7 & $(0,10,0,0)$ & 2 & $\mathrm{P}_{5}$ & \\
\hline & 7 & $(0,0,0,10)$ & 7 & $\mathrm{P}_{5}$ & Random: $(0.5,0.5,2,7)$ \\
\hline \multirow[t]{4}{*}{ Madrid } & 2 & $(0,0,0,10)$ & 9 & $P_{10}$ & Random: $(0.75,2,3,4.25)$ \\
\hline & 5 & $(0,10,0,0)$ & 1 & $\mathrm{P}_{20}$ & \\
\hline & 5 & $(0,0,0,10)$ & 2 & $\mathrm{P}_{5}$ & Accepted: $(0,0,2.5,7.5)$ \\
\hline & 6 & $(0,0,0,10)$ & 1 & $\mathrm{P}_{10}$ & Random: $(0,2,4,4)$ \\
\hline
\end{tabular}

Note: $\mathrm{L}_{\mathrm{i}}$ denotes the loss in Euro allocated to players with endowment level $\mathrm{i}$ and is a short form of $f_{i}(\xi)$ in the theoretical model. 
Table A4: Cross tables of individual and group-specific characteristics and proposals

\begin{tabular}{|c|c|c|c|c|c|c|c|c|c|}
\hline \multirow{2}{*}{$\begin{array}{l}\text { First ranked } \\
\text { theoretical } \\
\text { solution }\end{array}$} & \multicolumn{4}{|c|}{ Endowment } & \multicolumn{2}{|c|}{ Sex } & \multicolumn{3}{|c|}{ Family income } \\
\hline & $\begin{array}{c}5 \\
\text { Euros }\end{array}$ & $\begin{array}{c}10 \\
\text { Euros }\end{array}$ & $\begin{array}{c}15 \\
\text { Euros }\end{array}$ & $\begin{array}{c}20 \\
\text { Euros }\end{array}$ & Female & Male & Low & Middle & High \\
\hline $\begin{array}{l}\alpha=0: \\
\text { Equal losses }\end{array}$ & $\begin{array}{l}3 \\
(5.6 \%)\end{array}$ & $\begin{array}{l}4 \\
(7.8 \%)\end{array}$ & $\begin{array}{l}10 \\
(17.9 \%)\end{array}$ & $\begin{array}{l}10 \\
(18.9 \%)\end{array}$ & $\begin{array}{l}6 \\
(8.5 \%)\end{array}$ & $\begin{array}{l}21 \\
(14.7 \%)\end{array}$ & $\begin{array}{l}7 \\
(13.2 \%)\end{array}$ & $\begin{array}{l}6 \\
(9.1 \%)\end{array}$ & $\begin{array}{l}14 \\
(14.7 \%)\end{array}$ \\
\hline $\begin{array}{l}\alpha=1 / 5: \\
\text { Proportional }\end{array}$ & $\begin{array}{l}6 \\
(11.1 \%)\end{array}$ & $\begin{array}{l}2 \\
(3.9 \%)\end{array}$ & $\begin{array}{l}17 \\
(30.4 \%)\end{array}$ & $\begin{array}{l}15 \\
(28.3 \%)\end{array}$ & $\begin{array}{l}13 \\
(18.3 \%)\end{array}$ & $\begin{array}{l}27 \\
(18.9 \%)\end{array}$ & $\begin{array}{l}7 \\
(13.2 \%)\end{array}$ & $\begin{array}{l}17 \\
(25.8 \%)\end{array}$ & $\begin{array}{l}16 \\
(16.8 \%)\end{array}$ \\
\hline$\alpha=1 / 4$ & $\begin{array}{l}8 \\
(14.8 \%)\end{array}$ & $\begin{array}{l}5 \\
(9.8 \%)\end{array}$ & $\begin{array}{l}7 \\
(12.5 \%)\end{array}$ & $\begin{array}{l}8 \\
(15.1 \%)\end{array}$ & $\begin{array}{l}10 \\
(14.1 \%)\end{array}$ & $\begin{array}{l}18 \\
(12.6 \%)\end{array}$ & $\begin{array}{l}12 \\
(22.6 \%)\end{array}$ & $\begin{array}{l}4 \\
(6.1 \%)\end{array}$ & $\begin{array}{l}12 \\
(12.6 \%)\end{array}$ \\
\hline$\alpha=1 / 3$ & $\begin{array}{l}29 \\
(53.7 \%)\end{array}$ & $\begin{array}{l}14 \\
(27.5 \%)\end{array}$ & $\begin{array}{l}13 \\
(23.2 \%)\end{array}$ & $\begin{array}{l}16 \\
(30.2 \%)\end{array}$ & $\begin{array}{l}22 \\
(31.0 \%)\end{array}$ & $\begin{array}{l}50 \\
(35.0 \%)\end{array}$ & $\begin{array}{l}14 \\
(26.4 \%)\end{array}$ & $\begin{array}{l}26 \\
(39.4 \%)\end{array}$ & $\begin{array}{l}32 \\
(33.7 \%)\end{array}$ \\
\hline CEA & $\begin{array}{l}8 \\
(14.8 \%)\end{array}$ & $\begin{array}{l}26 \\
(51.0 \%)\end{array}$ & $\begin{array}{l}9 \\
(16.1 \%)\end{array}$ & $\begin{array}{l}4 \\
(7.6 \%)\end{array}$ & $\begin{array}{l}20 \\
(28.2 \%)\end{array}$ & $\begin{array}{l}27 \\
(18.9 \%)\end{array}$ & $\begin{array}{l}13 \\
(24.5 \%)\end{array}$ & $\begin{array}{l}13 \\
(19.7 \%)\end{array}$ & $\begin{array}{l}21 \\
(22.1 \%)\end{array}$ \\
\hline Total & $\begin{array}{l}54 \\
(100 \%)\end{array}$ & $\begin{array}{l}51 \\
(100 \%)\end{array}$ & $\begin{array}{l}56 \\
(100 \%)\end{array}$ & $\begin{array}{l}53 \\
(100 \%)\end{array}$ & $\begin{array}{l}71 \\
(100 \%)\end{array}$ & $\begin{array}{l}143 \\
(100 \%)\end{array}$ & $\begin{array}{l}53 \\
(100 \%)\end{array}$ & $\begin{array}{l}66 \\
(100 \%)\end{array}$ & $\begin{array}{l}95 \\
(100 \%)\end{array}$ \\
\hline Pearson chi ${ }^{2}$ & \multicolumn{4}{|c|}{$56.6925(\mathrm{p}<0.001)$} & \multicolumn{2}{|c|}{$3.6380(\mathrm{p}=0.457)$} & \multicolumn{3}{|c|}{$11.7821(\mathrm{p}=0.161)$} \\
\hline
\end{tabular}

Sample size $\mathrm{n}=214$. Antagonistic proposals are omitted. 
Table A4 (continued): Cross tables of individual and group-specific characteristics and proposals

\begin{tabular}{|c|c|c|c|c|c|c|c|c|c|c|c|}
\hline \multirow{2}{*}{$\begin{array}{l}\text { First ranked } \\
\text { theoretical } \\
\text { solution }\end{array}$} & \multicolumn{3}{|c|}{ Future income } & \multicolumn{3}{|c|}{ Political orientation } & \multicolumn{5}{|c|}{ Places } \\
\hline & Low & Middle & High & Left & Middle & Right & Berlin & Galway & Halle 2015 & Halle 2016 & Madrid \\
\hline $\begin{array}{l}\alpha=0: \\
\text { Equal losses }\end{array}$ & $\begin{array}{l}0 \\
(0.0 \%)\end{array}$ & $\begin{array}{l}4 \\
(12.9 \%)\end{array}$ & $\begin{array}{l}23 \\
(13.3 \%)\end{array}$ & $\begin{array}{l}13 \\
(18.8 \%)\end{array}$ & $\begin{array}{l}5 \\
(5.1 \%)\end{array}$ & $\begin{array}{l}9 \\
(19.6 \%)\end{array}$ & $\begin{array}{l}3 \\
(7.3 \%)\end{array}$ & $\begin{array}{l}7 \\
(13.5 \%)\end{array}$ & $\begin{array}{l}8 \\
(22.9 \%)\end{array}$ & $\begin{array}{l}3 \\
(6.5 \%)\end{array}$ & $\begin{array}{l}6 \\
(15.0 \%)\end{array}$ \\
\hline $\begin{array}{l}\alpha=1 / 5: \\
\text { Proportional }\end{array}$ & $\begin{array}{l}2 \\
(20.0 \%)\end{array}$ & $\begin{array}{l}14 \\
(45.2 \%)\end{array}$ & $\begin{array}{l}24 \\
(13.9 \%)\end{array}$ & $\begin{array}{l}15 \\
(21.7 \%)\end{array}$ & $\begin{array}{l}16 \\
(16.2 \%)\end{array}$ & $\begin{array}{l}9 \\
(19.6 \%)\end{array}$ & $\begin{array}{l}9 \\
(22.0 \%)\end{array}$ & $\begin{array}{l}10 \\
(19.2 \%)\end{array}$ & $\begin{array}{l}10 \\
(28.6 \%)\end{array}$ & $\begin{array}{l}3 \\
(6.5 \%)\end{array}$ & $\begin{array}{l}8 \\
(20.0 \%)\end{array}$ \\
\hline$\alpha=1 / 4$ & $\begin{array}{l}1 \\
(10.0 \%)\end{array}$ & $\begin{array}{l}5 \\
(16.1 \%)\end{array}$ & $\begin{array}{l}22 \\
(12.7 \%)\end{array}$ & $\begin{array}{l}4 \\
(5.8 \%)\end{array}$ & $\begin{array}{l}14 \\
(14.1 \%)\end{array}$ & $\begin{array}{l}10 \\
(21.7 \%)\end{array}$ & $\begin{array}{l}3 \\
(7.3 \%)\end{array}$ & $\begin{array}{l}8 \\
(15.4 \%)\end{array}$ & $\begin{array}{l}6 \\
(17.1 \%)\end{array}$ & $\begin{array}{l}4 \\
(8.7 \%)\end{array}$ & $\begin{array}{l}7 \\
(17.5 \%)\end{array}$ \\
\hline$\alpha=1 / 3$ & $\begin{array}{l}6 \\
(60.0 \%)\end{array}$ & $\begin{array}{l}5 \\
(16.1 \%)\end{array}$ & $\begin{array}{l}61 \\
(35.3 \%)\end{array}$ & $\begin{array}{l}26 \\
(37.7 \%)\end{array}$ & $\begin{array}{l}33 \\
(33.3 \%)\end{array}$ & $\begin{array}{l}13 \\
(28.3 \%)\end{array}$ & $\begin{array}{l}16 \\
(39.0 \%)\end{array}$ & $\begin{array}{l}23 \\
(44.2 \%)\end{array}$ & $\begin{array}{l}6 \\
(17.1 \%)\end{array}$ & $\begin{array}{l}14 \\
(30.4 \%)\end{array}$ & $\begin{array}{l}13 \\
(32.5 \%)\end{array}$ \\
\hline CEA & $\begin{array}{l}1 \\
(10.0 \%)\end{array}$ & $\begin{array}{l}3 \\
(9.7 \%)\end{array}$ & $\begin{array}{l}43 \\
(24.9 \%)\end{array}$ & $\begin{array}{l}11 \\
(15.9 \%)\end{array}$ & $\begin{array}{l}31 \\
(31.3 \%)\end{array}$ & $\begin{array}{l}5 \\
(10.9 \%)\end{array}$ & $\begin{array}{l}10 \\
(24.4 \%)\end{array}$ & $\begin{array}{l}4 \\
(7.7 \%)\end{array}$ & $\begin{array}{l}5 \\
(14.3 \%)\end{array}$ & $\begin{array}{l}22 \\
(47.8 \%)\end{array}$ & $\begin{array}{l}6 \\
(15.0 \%)\end{array}$ \\
\hline Total & $\begin{array}{l}10 \\
(100 \%)\end{array}$ & $\begin{array}{l}31 \\
(100 \%)\end{array}$ & $\begin{array}{l}173 \\
(100 \%)\end{array}$ & $\begin{array}{l}69 \\
(100 \%)\end{array}$ & $\begin{array}{l}99 \\
(100 \%)\end{array}$ & $\begin{array}{l}46 \\
(100 \%)\end{array}$ & $\begin{array}{l}41 \\
(100 \%)\end{array}$ & $\begin{array}{l}52 \\
(100 \%)\end{array}$ & $\begin{array}{l}35 \\
(100 \%)\end{array}$ & $\begin{array}{l}46 \\
(100 \%)\end{array}$ & $\begin{array}{l}40 \\
(100 \%)\end{array}$ \\
\hline Pearson $\mathrm{chi}^{2}$ & \multicolumn{3}{|c|}{$23.8821(\mathrm{p}=0.002)$} & \multicolumn{3}{|c|}{$22.9805(\mathrm{p}=0.003)$} & \multicolumn{5}{|c|}{$39.9404(\mathrm{p}=0.001)$} \\
\hline
\end{tabular}

Sample size $\mathrm{n}=214$. Antagonistic proposals are omitted. 